\title{
Synthesis and processing of silicon nitride and related materials using preceramic polymer and non-oxide sol-gel approaches
}

\author{
Andrew L. Hector \\ Chemistry, University of Southampton, Highfield, Southampton SO17 1BJ \\ A.L.Hector@soton.ac.uk
}

\begin{abstract}
The use of preceramic polymer and sol-gel processing methods in the production of silicon nitride and a number of related materials is reviewed. Amorphous ceramics in this system, that may contain additional carbon, boron and other elements, have a number of promising and/or useful high temperature properties. These include good mechanical properties and oxidation resistance at temperatures that can exceed $1500{ }^{\circ} \mathrm{C}$ with some materials, but also useful charge storage capability, catalytic activity and semiconducting or optical properties after doping.
\end{abstract}

\section{Introduction}

Silicon nitride adopts two main structures formed from corner sharing tetrahedra, with $\alpha-\mathrm{Si}_{3} \mathrm{~N}_{4}$ adopting a simple hexagonal close packing arrangement and $\beta-\mathrm{Si}_{3} \mathrm{~N}_{4}$ a more complex stacking sequence of the close packed layers [1]. It is often used as a hard material, and the cubic spinel high pressure form, which has been called c- $\mathrm{Si}_{3} \mathrm{~N}_{4}$, has a high bulk modulus value of 290(5) GPa [2,3]. Conventional thermal ceramic processing of silicon nitride and related materials is limited by the very high temperatures required to achieve any mobility. Spark plasma sintering at $1500-1700{ }^{\circ} \mathrm{C}$, just below the decomposition to the elements at $\sim 1850{ }^{\circ} \mathrm{C}$, may be used to produce compacts and molten sintering aids can reduce the sintering temperatures somewhat [4]. Under these conditions $\beta-\mathrm{Si}_{3} \mathrm{~N}_{4}$ is the thermodynamically stable phase and hence this is the most used in engine parts, bearings and high temperature ceramics [5]. Amorphous silicon nitride ceramics with random arrangements of the corner sharing $\mathrm{SiN}_{4}$ tetrahedra, and compositions also containing carbon, boron or other elements, have become important over recent decades and these require different routes for their manufacture.

Amorphous silicon nitride films are used extensively as dielectric materials in electronics, and can be prepared by a range of sputtering and chemical vapour deposition (CVD) techniques using simple molecular precursors such as $\mathrm{SiH}_{4}, \mathrm{SiCl}_{4}$, amides or silazanes with ammonia or nitrogen [6]. The hardness and oxidation resistance of silicon nitride and carbonitride films also lends them to applications in wear and corrosion protection, and plasma enhanced CVD can produce thin, dense films [7-9]. These often contain a significant fraction of hydrogen, and are typically amorphous. CVD is also an effective approach to the formation of some composite materials, e.g. the coating of SiC fibres with silicon borocarbonitride to improve their mechanical properties [10]. Whilst CVD can be used to produce bulk materials including silicon carbonitrides [11], it offers slow growth rates and limited capability to control the morphology of the product.

Silicon based polymers such as polysiloxanes and polysilazanes have wide applications as coatings, adhesives and objects, and their applications as precursors to ceramic materials were first developed in the mid-1960s [12]. A key advantage is the possibility of shaping the polymer then applying a thermal treatment, sometimes in an active gaseous environment such as ammonia, to convert the 
polymer to a ceramic with the desired shape or morphology. A number of authors have previously reviewed precursor chemistry, processing and commercial applications in this area [12-14] and more recent reviews have examined production of fibres [15], 1D nanostructures [16] and ordered mesoporous materials [17].

Sol-gel processing involves the solution phase development of polymeric or colloidal species and their controlled gelation followed by solvent removal to make powders and porous or dense objects $[18,19]$. A particularly strong aspect of the utility of the sol-gel approach is its ability to form materials around hard or soft templates that can be later removed, leaving structures with controlled porosities [20]. In 1995 Riedel reviewed preceramic routes to ceramics and commented that: "The sol-gel route is applied largely for the synthesis of oxide ceramics, while the polymerpyrolysis route is applied largely for the preparation of non-oxide ceramics" [21]. Sol-gel processing was indeed developed for the production of silica objects and the bulk of the sol-gel literature has further developed the methods for the production of other metal oxides and for organic-inorganic hybrid materials [22]. However, its applications for non-oxide materials have also developed significantly since Riedel's comment [23].

This review aims to summarise the state of the art in production of silicon nitride and related materials using preceramic polymers and sol-gel processing methods. The unifying theme is the use of molecular precursors followed by a cross-linking process and a thermal treatment under controlled gas environment to enact decomposition with loss of unwanted constituents. A broad range of applications and potential applications exist for this broad group of materials.

\section{Reactions of molecular precursors with ammonia to produce silicon nitride and related materials}

A brief discussion of molecular precursor ammonolysis is warranted in the context of a review of preceramic and sol-gel routes to silicon nitride as it merely shifts the point in processing at which a polymeric structure containing silicon, nitrogen, and possibly other required elements, is formed. Ammonia will typically attack silicon centres to yield $\mathrm{Si}-\mathrm{NH}_{2}$ groups and liberate one of the other functional groups in protonated form, then the $\mathrm{Si}^{-\mathrm{NH}_{2}}$ groups will similarly attack a neighbouring centre to make imide linkages, e.g. [5]:

$$
\begin{gathered}
\mathrm{SiCl}_{4}+2 \mathrm{NH}_{3} \stackrel{0^{\circ} \mathrm{C}}{\longrightarrow} \mathrm{SiCl}_{3}\left(\mathrm{NH}_{2}\right)+\mathrm{NH}_{4} \mathrm{Cl} \\
n \mathrm{SiCl}_{3}\left(\mathrm{NH}_{2}\right)+4 n \mathrm{NH}_{3} \stackrel{0^{\circ} \mathrm{C}}{\longrightarrow}\left[\mathrm{Si}(\mu-\mathrm{NH})_{2}\right]_{n}+3 n \mathrm{NH}_{4} \mathrm{Cl}
\end{gathered}
$$

Further condensation of these imide linkages can then occur at high temperature to provide nitride groups, although often some hydrogen will remain in the structure:

$$
3\left[\mathrm{Si}(\mu-\mathrm{NH})_{2}\right]_{n} \stackrel{1000^{\circ} \mathrm{C}}{\longrightarrow} n \mathrm{Si}_{3} \mathrm{~N}_{4}+2 n \mathrm{NH}_{3}
$$

The clearest example of this process is the isolation of a crystalline intermediate, $\mathrm{Si}_{2} \mathrm{~N}_{2}(\mathrm{NH})$ (Fig. 1), from the reaction of the cyclic polysilazane $\left[\mathrm{Me}_{2} \mathrm{Si}(\mu-\mathrm{NH})\right]_{4}$ with ammonia followed by decomposition of the product at $1350{ }^{\circ} \mathrm{C}$ to make $\mathrm{Si}_{3} \mathrm{~N}_{4}$ [24]. In some cases this process can also be effective in the control of morphology, e.g. the development of porosity in mesoporous [25-27] silicon imidonitride for base catalysis applications simply by adjusting the species present and heating parameters during the decomposition of the silicon diimide precursor. Ordered macroporous films have even been produced directly from the infiltration of a $\mathrm{Si}(\mathrm{NHMe})_{4}$ solution into a polystyrene opal template, exposure to ammonia and then firing in ammonia (Fig. 2) [28]. 


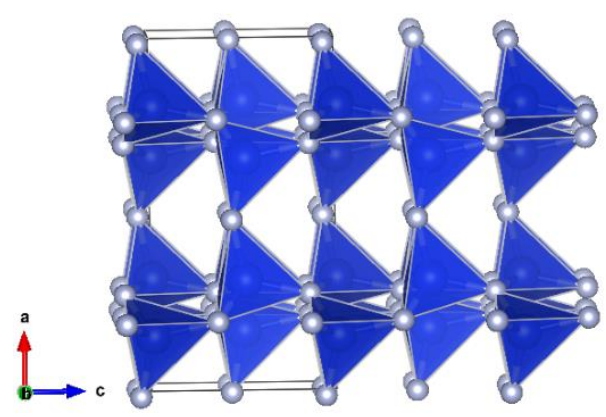

Figure 1: Crystal structure of $\mathrm{SiN}_{2}(\mathrm{NH})$ showing the double layers of corner-linked $\mathrm{SiN}_{4}$ tetrahedra with nitride ( $\left.\mathrm{NSi}_{3}\right)$ groups within the layers and bridging imide ( $\mathrm{NHSi}_{2}$ ) groups between the layers [29].

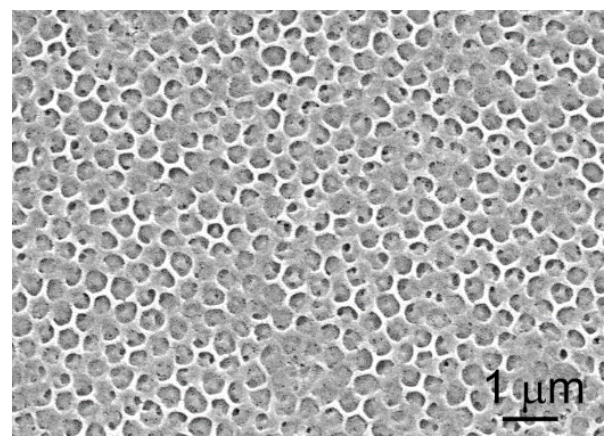

Figure 2: Scanning electron micrograph of the top surface of a thin film of ordered macroporous silicon nitride. Reproduced with kind permission from [28].

In a small number of cases single molecule precursors have been used to introduce heteroatoms into silicon nitride and make ternary or quaternary materials. A boryl substituted trisilazane $\left[\mathrm{Me}_{2} \mathrm{SiN}\left\{\mathrm{B}(\mathrm{F}) \mathrm{N}\left(\mathrm{SiMe}_{3}\right)_{2}\right\}\right]_{3}$ (Fig. 3) and more complex structures have been thermally converted to silicon boron carbonitride and then crystallised to produce composite powders [30]. High surface area silicon aluminium nitride has been produced from [EtAl( $\left.\mu-\mathrm{NHEt})(\mu-\mathrm{NEt})_{2} \mathrm{Si}(\mathrm{NHEt})\right]_{2}$ (Fig. 3), although this was believed to have partly dissociated during thermal treatment and 200 Bar pressure was required to maintain a 1:1 Si:Al ratio [31]. A generally applicable approach to the incorporation of metals into silicon nitride reacted $\mathrm{LiHNSi}\left(\mathrm{NMe}_{2}\right)_{3}$ with $\mathrm{TiCl}_{4}$ to produce $\left[\left\{\left(\mathrm{Me}_{2} \mathrm{~N}\right)_{3} \mathrm{SiNH}\right\}_{2} \mathrm{Ti}\left\{\mu-\mathrm{NSi}\left(\mathrm{NMe}_{2}\right)_{3}\right\}_{2} \mathrm{Ti}\left\{\mathrm{NHSi}\left(\mathrm{NMe}_{2}\right)_{3}\right\}_{2}\right]$ (Fig. 3) [32]. This was insoluble, but was treated under ammonia at $160^{\circ} \mathrm{C}$ and $15 \mathrm{Bar}$ to produce a mixed imide that could be fired at $1000^{\circ} \mathrm{C}$ to make a titanium nitride-silicon nitride composite. Zirconium and hafnium analogues were also produced by a similar route [33]. It is noteworthy that, whilst this is elegant chemistry, the precursors are complex, their high molecular weights often result in insolubility, they may not retain their bonded structures during decomposition and the silicon to heteroatom ratios are defined by the precursor and so are inflexible in terms of product composition. 

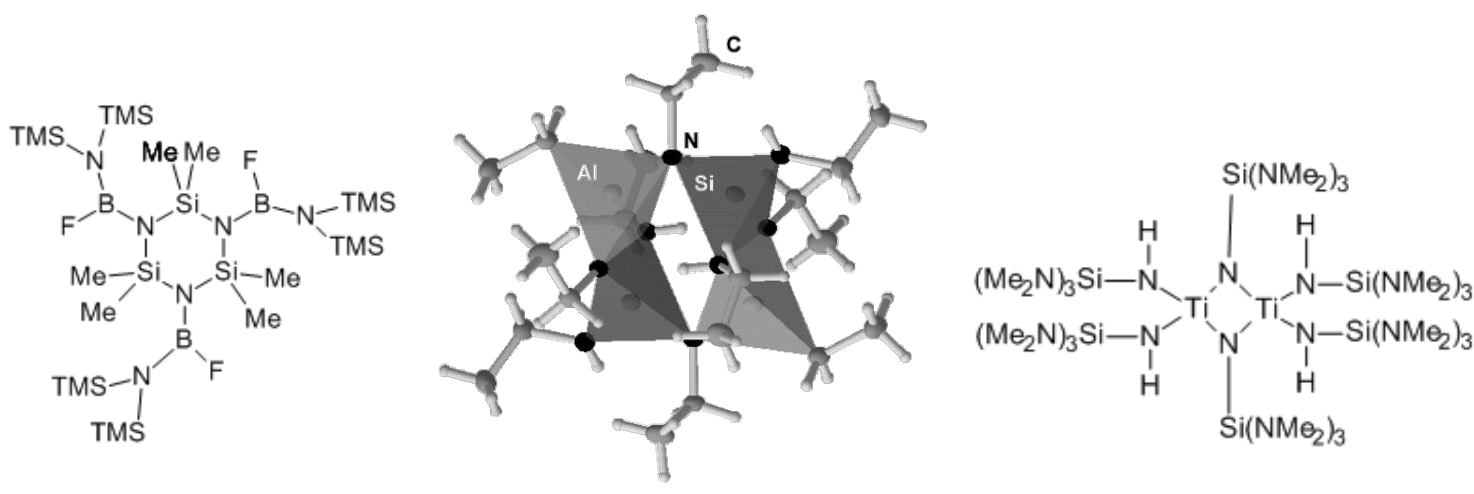

Figure 3: Structures of single source precursors to Si-B-N (left), Si-Al-N (centre) and Si-Ti-N (right) ceramics and composites [30-32]. Central image reproduced with kind permission from [31].

\section{Preceramic routes to silicon nitride and related materials}

Initial interest in use of preceramic polymers for the production of silicon nitride and carbide derived from a desire to produce ceramic-fibre composites with superior properties, especially at high temperature, compared with those of carbon-carbon fibre composites [34]. The early work of Verbeek and co-workers at Bayer used $\mathrm{MeSiCl}_{3}$ and $\mathrm{MeNH}_{2}$ to produce a bicyclic silazane that could be converted to an organic solvent-soluble resin at $520^{\circ} \mathrm{C}$, melt-spun into fibres at $220^{\circ} \mathrm{C}$ and

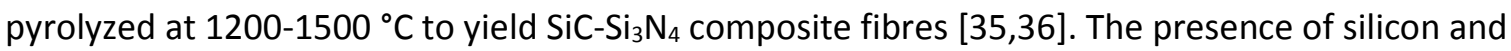
nitrogen in the polysilazane polymer backbone and carbon substituent groups as a source of carbide is a common theme in much of the precursor chemistry to Si-C-N materials, although several variations on this theme will be explored. Ease of processability into a ceramic product requires the polymer to be meltable or soluble, but then to retain a stable shape to undergo high temperature decomposition to the desired composition with high ceramic yield. Verbeek's work used a period of heating in moist air at $110^{\circ} \mathrm{C}$ to render the polymer infusible, with incorporation of oxygen into the surfaces at least, and then offered a ceramic yield during the final pyrolysis of just $45 \%$.

\subsection{Perhydropolysilazanes in silicon nitride formation}

Perhydropolysilazanes contain no carbon so should be the ideal sources of carbon-free silicon nitride. They are formed from the reaction of a silane or silicon chloride with ammonia, most frequently the silicon source is $\mathrm{SiCl}_{2} \mathrm{H}_{2}$ :

$$
n \mathrm{SiCl}_{2} \mathrm{H}_{2}+3 n \mathrm{NH}_{3} \rightarrow\left[\mathrm{H}_{2} \mathrm{SiNH}\right]_{n}+2 n \mathrm{NH}_{4} \mathrm{Cl}
$$

Carrying out this reaction in standard organic solvents, or using various other silicon sources, produced polymers that could not be processed. However, carrying out the reaction in pyridine, soluble polymers that could be spun into fibres were obtained [37]. The same material is produced commercially by Merck as a spin-on dielectric. Presumably the coordinating pyridine solvent in this synthesis limits the size of oligomers that are produced. Of course the use of such a coordinating solvent in the manufacture of the polymer means that the polymer is not truly carbon-free, and any solvent used to process the polymer before firing is also a potential source of carbon. Mass spectrometry studies carried out during thermal decomposition of a perhydropolysilazane polymer in ammonia have revealed the evaporation of residual solvent below $400^{\circ} \mathrm{C}$ is the main reason for the weight loss [38]. Between 400 and $600^{\circ} \mathrm{C}$ ammonia reacts with silicon centres in the polymer containing $\mathrm{Si}-\mathrm{H}$ bonds, with evolution of hydrogen, and the resulting amide groups can undergo further reactions with neighbouring silicon centres resulting in cross-linking. The formation of an amorphous hydrogenated solid with structural features that closely resemble $\mathrm{Si}_{3} \mathrm{~N}_{4}$ in pair 
distribution function studies (i.e. consist mainly of corner sharing $\mathrm{SiN}_{4}$ tetrahedra) [39] occurs between $600-1000{ }^{\circ} \mathrm{C}$, although even after heating to $1000^{\circ} \mathrm{C}$ in ammonia the product can still contain small quantities (0.2\%) of carbon [38]. Ceramic yields are close to $100 \%$ when pyrolysis is carried out in ammonia, but in inert gas Isoda found ceramic yields of $82-93 \%$ depending on the processing conditions of the polymer [37]. The variation could be linked directly to the degree of polymer cross-linking. Ceramics produced under inert gas are black and have $\mathrm{Si} \mathrm{N}$ ratios close to the $1: 1$ value in the polymer itself, so the reactions of the ammonia during the pyrolysis are crucial to delivering white ceramics with compositions close to $\mathrm{Si}_{3} \mathrm{~N}_{4}$. Crystallisation occurs in the bulk of the sample by $1270{ }^{\circ} \mathrm{C}$ and is complete by $1400^{\circ} \mathrm{C}$, with $\mathrm{Si}$ and $\mathrm{Si}_{3} \mathrm{~N}_{4}$ produced in nitrogen or just $\mathrm{Si}_{3} \mathrm{~N}_{4}$ in ammonia [40].

Perhydropolysilazane-derived $\mathrm{Si}_{3} \mathrm{~N}_{4}$ fibres (Fig. 4) with a diameter of $\sim 10 \mu \mathrm{m}$ were found to have a density of $2.5 \mathrm{~g} \mathrm{~cm}^{-3}$ (the crystalline phases have $3.2 \mathrm{~g} \mathrm{~cm}^{-3}$ [1]), tensile strength of 1.7-2.2 $\mathrm{GPa}$ and tensile modulus of 180-200 GPa [41]. These fibres were intended as reinforcing components in composite materials. Preparation of composite ceramic bodies by hot pressing the fibres with a series of matrix materials showed that they were stable in $\mathrm{Si}_{3} \mathrm{~N}_{4}, \mathrm{ZrN}, \mathrm{TiC}, \mathrm{ZrB}_{2}$ and, if hot pressed without sintering additives, $\mathrm{Al}_{2} \mathrm{O}_{3}$ [41]. $\mathrm{SiO}_{2}, \mathrm{ZrO}_{2}$, yttria stabilised zirconia and $\mathrm{Al}_{6} \mathrm{Si}_{2} \mathrm{O}_{13}$ all reacted with the fibre surfaces and were unsuitable as matrix materials. The key conclusion was that for these more reactive oxide materials the fibres would need to be coated to improve stability.

It is noteworthy that fibrous components ("fibrils") have been found in addition to polycrystalline material even in $\mathrm{Si}_{3} \mathrm{~N}_{4}$ compacts derived purely from perhydropolysilazane [42], and hence even these materials can be considered as composites. Indeed these preceramic polymers have also been used with nanoparticle catalysts for the controlled growth of single crystal $\mathrm{Si}_{3} \mathrm{~N}_{4}$ nanowires and branched structures $[43,44]$. However the largest number of reports come from using it as the matrix phase in composite materials. Use of perhydropolysilazane as the binder phase in the development of ceramic bodies from silicon nitride powders results in enhanced densification in the absence of pressure and a larger proportion of the high temperature $\beta-\mathrm{Si}_{3} \mathrm{~N}_{4}$ phase even at the moderate temperature of $800^{\circ} \mathrm{C}[45,46]$. Sato et al dispersed carbon fibres into

perhydropolysilazane and fired to produce composites in which the fibres were firmly embedded as judged by a lack of fibre "pull-out" after fracturing (Fig. 4) and with good flextural strength [47]. Addition of $\mathrm{SiC}$ whiskers improved the strength still further. The ultimate strength of such composites is limited by the lower crystallisation temperature of the $\mathrm{Si}_{3} \mathrm{~N}_{4}$ matrix phase compared with carbon or boron doped modifications [48]. Qi et al linked good adhesion between woven $\mathrm{SiO}_{2}$ fibres and a perhydropolysilazane-derived $\mathrm{Si}_{3} \mathrm{~N}_{4}$ matrix to a tendency to cause brittle fracture, and pre-coated the fibres to reduce this adhesion leading to a 4-fold increase in strength accompanied by an increase in "pull-out" during fracture (Fig. 4) [49].
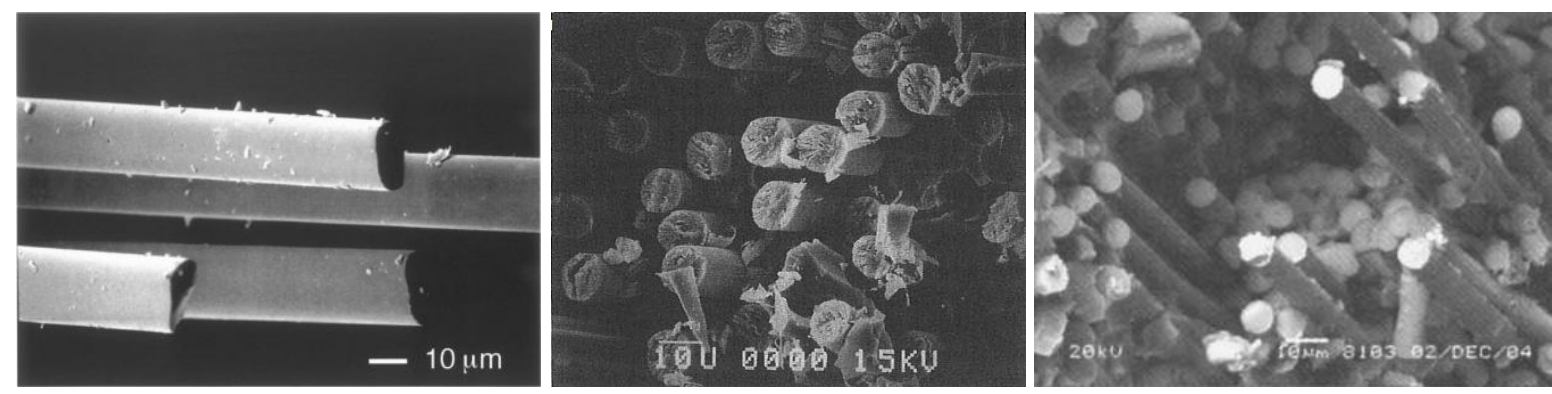

Figure 4: Perhydropolysilazane derived $\mathrm{Si}_{3} \mathrm{~N}_{4}$ fibres (left), a fracture surface in a carbon fibre-silicon nitride composite (centre) and a fracture surface in a silica fibre-silicon nitride composite (right). Reproduced with kind permission from $[41,47,49]$. 
Ordered mesoporous $\mathrm{Si}_{3} \mathrm{~N}_{4}$ from perhydropolysilazane has high surface area $\left(772 \mathrm{~m}^{2} \mathrm{~g}^{-1}\right)$ and can be used as a support for Pt nanoparticles used in borohydride decomposition [50].

Silicon oxynitride films produced by dip-coating from perhydropolysilazane solution in dibutyl ether, with oxygen picked up from processing steps carried out in air, were hard, dense and homogeneous with good corrosion barrier properties after heating in nitrogen at $1000^{\circ} \mathrm{C}$ [51]. Heating in air resulted in higher ceramic yield and less shrinkage due to further cross-linking, presumably utilising water vapour in the air. The surfaces were strongly oxidised, but at $600^{\circ} \mathrm{C}$ a weak nitrogen signal was still observable in the $\mathrm{X}$-ray photoelectron spectra suggesting some nitride remained even in the top $10 \mathrm{~nm}$ of the films [52]. Shinde et al showed spin-on thin films of perhydropolysilazane to be converted to amorphous silicon nitride after heating to $80^{\circ} \mathrm{C}$ then exposing to UV light, suggesting they could be used as an antireflection coating in photolithography [53]. Similar spin-on coatings on glass or polyethyl terephthalate were thermally annealed at 60 or $200{ }^{\circ} \mathrm{C}$, and were then shown to be scratch-resistant and hydrophobic with potential applications in coating of optics [54].

\subsection{Polyorganosilazanes in silicon nitride and carbonitride formation}

The inclusion of organic substituents on the polysilazane polymer allows adjustment of their properties and can provide for the controlled formation of silicon carbonitrides. The incorporation of carbon improves chemical and oxidation resistance, increases the crystallisation temperature and provides access to $\mathrm{SiC}-\mathrm{Si}_{3} \mathrm{~N}_{4}$ composites after crystallisation [13]. The synthesis of polyorganosilazanes typically involves the ammonolysis or aminolysis of an organosilicon chloride:

$$
n \mathrm{RR}^{\prime} \mathrm{SiCl}_{2}+3 n \mathrm{R}^{\prime \prime} \mathrm{NH}_{2} \rightarrow\left[\mathrm{RR}^{\prime} \mathrm{SiNR}^{\prime \prime}\right]_{n}+2 n \mathrm{R}^{\prime \prime} \mathrm{NH}_{2} \cdot \mathrm{HCl} \quad\left(\mathrm{R}, \mathrm{R}^{\prime}, \mathrm{R}^{\prime \prime}=\text { organic group or } \mathrm{H}\right)
$$

A number of compositions that have been used as preceramics are listed in Table 1. Separation of the polymer from the ammonium chloride or amine hydrochloride by-product is difficult, but a number of polyureasilizane materials are commercially available from KiON (Ceraset branding) and Merck (Durazane). A mixture of two chlorosilanes in the polymerisation process can be used to tune the composition of the polymer by mixing substituent groups [55], and mixtures of ammonia and amine can be used to tune composition at $\mathrm{N}$ [56]. The mixed $\mathrm{Me}_{x} \mathrm{SiCl}_{4-\mathrm{x}}$ distillation waste product from the Müller-Rochow synthesis has even been used as a precursor to blended polymers to make a variety of silicon carbonitride ceramics [57]. With some side groups such as vinyl the replacement of ammonia with the more reactive hydrazine may be necessary [58], this can incorporate diazane linkages $(-\mathrm{N}=\mathrm{N}-)$ into the polymer but these decompose at around $300^{\circ} \mathrm{C}[59]$. Ceraset is formed of large cyclic oligomers with a mixture of methyl, vinyl and protons on the silicon and $\mathrm{NH}$ groups, but then a urea-derived group linking the ring [60]. 
Table 1: Polyorganosilazanes of the form $\left[\mathrm{RR}^{\prime} \mathrm{SiNR}^{\prime \prime}\right]_{n}$ used in the production of silicon nitride and carbonitride

\begin{tabular}{llll}
\hline $\mathrm{R}(-\mathrm{Si})$ & $\mathrm{R}^{\prime}(-\mathrm{Si})$ & $\mathrm{R}^{\prime \prime}(-\mathrm{N})$ & References \\
\hline $\mathrm{Me}$ & $\mathrm{H}$ & $\mathrm{H}$ & {$[49,59,61,62]$} \\
$\mathrm{Me}$ & $\mathrm{Me}+\mathrm{H}$ & $\mathrm{H}$ & {$[48,55,63-77]$} \\
$\mathrm{Me}$ & $\mathrm{Me}$ & $\mathrm{H}$ & {$[78]$} \\
$\mathrm{Me}+\mathrm{H}$ & $\mathrm{H}$ & $\mathrm{H}$ & {$[79][56]$} \\
$\mathrm{Hex}$ & $\mathrm{Me}$ & $\mathrm{H}$ & {$[63,80]$} \\
$\mathrm{Vi}$ & $\mathrm{H}$ & $\mathrm{H}$ & {$[81,82]$} \\
$\mathrm{Vi}$ & $\mathrm{Me}$ & $\mathrm{H}$ & {$[58,79,83]$} \\
$\mathrm{Vi}+\mathrm{H}$ & $\mathrm{Me}$ & $\mathrm{H}$ & {$[60,84-105] *$} \\
$\mathrm{Vi}+\mathrm{Me}$ & $\mathrm{H}$ & $\mathrm{H}$ & {$[82,106]$} \\
$\mathrm{Ph}$ & $\mathrm{Me}$ & $\mathrm{H}$ & {$[79]$} \\
$\mathrm{Ph}$ & $\mathrm{Vi}$ & $\mathrm{H}$ & {$[107]$} \\
$\mathrm{H}$ & $\mathrm{H}$ & $\mathrm{Me}+\mathrm{H}$ & {$[56]$} \\
$\mathrm{H}$ & $\mathrm{H}$ & $\mathrm{Me}$ & {$[108]$} \\
$\mathrm{Vi}$ & $\mathrm{H}$ & $\mathrm{Me}$ & {$[82]$} \\
\hline
\end{tabular}

( $\mathrm{Me}=$ methyl; $\mathrm{Vi}=$ vinyl; Hex = hexyl; $\mathrm{Ph}=$ phenyl; *includes Ceraset, which also contains urea substituents)

The mainly linear polymers described in Table 1 are typically cross-linked with a strong base, by exposure to moist air or by hydrosilylation reactions involving $\mathrm{Si}-\mathrm{H}$ or vinyl side groups in order to maintain shape and increase ceramic yield during firing. Cross-links often lead to the formation of cyclic structures within the polymer and these also help to reduce the loss of mass during firing [109]. However, these cross-links can also be developed during synthesis, e.g. by co-ammonolysis of $\mathrm{MeHSiCl}_{2}$ with $\mathrm{HSiCl}_{3}$ to make a blended polymer that provides a higher ceramic yield than more linear structures [80]. Ammonolysis of $\mathrm{ViSiCl}_{3}$ results in more cross-links than the dichloride and a composition [ViSi $\left.(\mathrm{NH})_{1.5}\right]_{n}$, whilst the reactive vinyl groups allow for further thermal cross-linking of the polymer [85]. The degree of crosslinking obtained during polymer synthesis can also be modified by blending precursors with two or three reactive chloride groups to make $\left[\mathrm{ViSi}(\mathrm{NH})_{1.5}\right]_{m}[\mathrm{MeHSiNH}]_{n}$ [84,110-112]. A metathesis reaction of $\mathrm{CySiCl}_{3}\left(\mathrm{Cy}=\right.$ cyclohexyl) with $\mathrm{Li}_{3} \mathrm{~N}$ directly produced a polymer that was very strongly cross-linked and insoluble without further treatment [113].

Bao and Edirisinghe produced polycyclosilazane polymers as shown in Fig. 5, with a second variant replacing the phenyl groups with protons [114]. The direct silicon-silicon bonds make these compounds distinct from most other polymers used for silicon nitrides. These were mixed with a polysilane to produce $\mathrm{SiC}-\mathrm{Si}_{3} \mathrm{~N}_{4}$ composites, with and without a Si powder filler, with very well controlled Si:C:N ratios. Larger numbers of proton substituents were found to increase the ceramic yields due to their higher reactivity and hence an increased level of crosslinking [115].
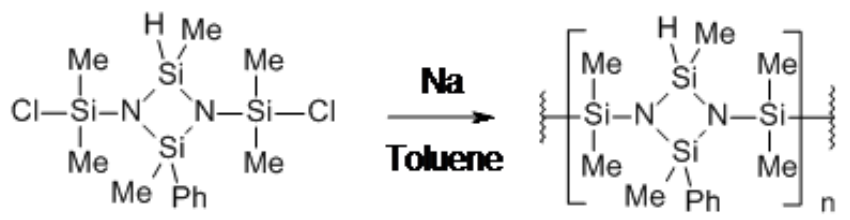

Figure 5: Synthesis of polycyclosilazane precursors [114].

Bill et al reviewed the ceramisation of the polymers into amorphous ceramics in 2001 and noted the importance of MAS-NMR, IR spectroscopy and mass spectrometry of the evolved gases in understanding these reactions (Fig. 6) [13]. Polyhydromethylsilazane polymers condense via radical reactions of the hydrogen and methyl substituents from around $500{ }^{\circ} \mathrm{C}$, and these can produce bridging methylene groups with evolution of methane or hydrogen. Condensation of bridging imide groups to form further Si-N bonds occur from around the same temperature, and these can lead to 
the elimination of methane and a reduction in the number of $\mathrm{Si}-\mathrm{C}$ bonds present. By around $1050{ }^{\circ} \mathrm{C}$ the material contains mainly $\mathrm{SiN}_{4}, \mathrm{SiN}_{3} \mathrm{C}, \mathrm{SiN}_{2} \mathrm{C}_{2}$ and $\mathrm{CSi}_{4}$ tetrahedral units, although some phase separated $s p^{2}$ carbon can also be detected due to pyrolysis of the methane by-product. Vinyl sidegroups polymerise from around $300^{\circ} \mathrm{C}$ and so these polymers develop new crosslinks at lower temperature, but homolytic $\mathrm{Si}-\mathrm{C}$ cleavage occurs as the temperature is raised further and hence the $s p^{2}$ carbon content is higher. Transamination reactions can also result in ammonia evolution and hence nitrogen loss between 200 and $500{ }^{\circ} \mathrm{C}$. With controlled crosslinking and thermolysis these polymers can produce fully dense amorphous silicon carbonitride compacts [97].

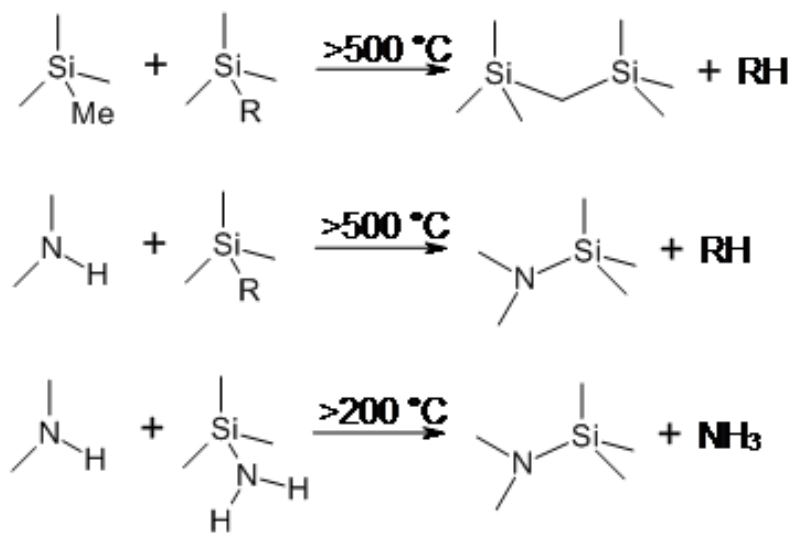

Figure 6: Common moderate temperature reactions in the ceramisation of polyorganosilazanes $(R=M e$ or $H)$.

Riedel et al showed that compacts of a polyhydromethylsilazane produced from a mixture of $\mathrm{Me}_{2} \mathrm{SiCl}_{2}$ and $\mathrm{MeHSiCl}_{2}$ with ammonia crystallised to $\alpha-\mathrm{Si}_{3} \mathrm{~N}_{4}$ in ammonia above $1000{ }^{\circ} \mathrm{C}$, SiC in $\mathrm{Ar}$ above $1400^{\circ} \mathrm{C}$ or $\alpha-\mathrm{Si}_{3} \mathrm{~N}_{4}$ and $\mathrm{SiC}$ in nitrogen above $1600^{\circ} \mathrm{C}$ [55]. Pre-treatment in ammonia at moderate temperature before firing in nitrogen can increase the nitrogen content and reduce the crystallisation temperatures of compacts produced from polyhydromethylsilazane-derived [77] and vinyl-containing polysilazanes [86]. Interestingly high nitrogen overpressures during firing can also increase nitrogen content and reduce crystallisation temperature [76], again suggesting that some incorporation of nitrogen from the diatomic gas can also occur. Gerardin et al showed that polyvinylsilazanes underwent segregation of the carbon in the amorphous ceramic phase, but SiC and $\mathrm{Si}_{3} \mathrm{~N}_{4}$ formed during crystallisation [82]. These are cleanly segregated into separate grains in the crystallised ceramics according to TEM [13] and PDF studies [79]. Interestingly the formation of $\mathrm{SiN}_{4}$ and $\mathrm{SiC}_{4}$ groups from $\mathrm{SiN}_{3} \mathrm{C}$ has positive enthalpy and entropy, so this segregation appears to be entropy favoured and driven by the elevated temperature [116]. This process has also been followed ex situ by NMR [116]. Compacts sintered in argon at $1000^{\circ} \mathrm{C}$ were resistant to air oxidation up to $1600{ }^{\circ} \mathrm{C}$ due to the formation of an $\mathrm{SiO}_{2}$ surface layer a few $\mu \mathrm{m}$ thick [65]. A number of metal alkoxides have also been used to treat surfaces and improve oxidation resistance[117]. Powders oxidise more extensively [74]. At high temperatures these ceramics can undergo some creep deformation, but harden during this process and become highly creep resistant [118]. Laine et al reported that in poly-N-methylsilazane crystallisation was strongly inhibited up to $1400^{\circ} \mathrm{C}$, in contrast with the analogue with methyl groups on the silicon which crystallised under these conditions [108].

Polymer-derived amorphous $\mathrm{SiCN}$ shows significant variation in its mechanical properties due to pores and carbon-rich domains, but its hardness has been measured at $\sim 13 \mathrm{GPa}$, in between those of $\mathrm{SiO}_{2}$ glass $(9 \mathrm{GPa})$ and polycrystalline $\mathrm{Si}_{3} \mathrm{~N}_{4}(25 \mathrm{GPa})$ [73]. These materials provide low friction surfaces and are highly wear resistant, with these properties improving as firing temperature is increased short of crystallisation [91]. It can be produced with complex morphologies, including 
microfabrication of sub-mm gears and other high temperature MEMs devices [94], and resistancetemperature detectors (Fig. 7) [102]. Spherical particles may be formed by precipitation of polymer spheres followed by thermal processing (Fig. 7) [101].
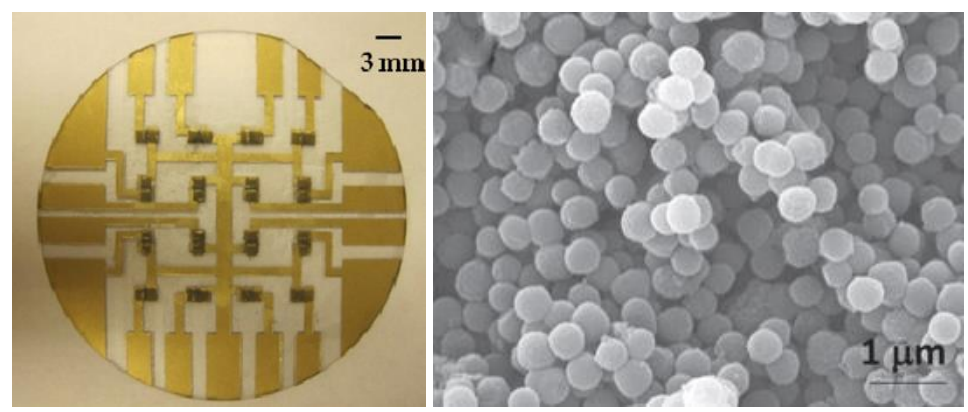

Figure 7: A silicon carbonitride resistance-temperature detector array with gold contacts to the individual sensor elements, and silicon carbonitride microspheres obtained by controlled precipitation of polymer spheres and pyrolysis at $1300^{\circ} \mathrm{C}$. Reproduced with kind permission from [101,102].

In the presence of an $\mathrm{FeCl}_{2}$ catalyst single crystal nanobelts [88] or nanowires [89] can be grown from the surface of a Ceramset-derived amorphous silicon carbonitride. A liquid phase growth mechanism was proposed due to a lack of droplets at the end of the wires/belts, but in $\mathrm{FeCl}_{2-}$ catalysed growth of branched structures from polymethylsilazane a more conventional vapourliquid-solid growth mechanism was suggested [61].

Hot pressing of polyvinylsilazane into an amorphous carbonitride results in significantly reduced porosity compared with cold pressing followed by firing [81]. Schonfelder et al showed that $96 \%$ dense silicon carbonitride compacts could be produced from polyhydromethylsilazane by thermal decomposition, producing a porous compact from the powder and then infiltrating this with further polymer before firing [64]. Butyl polysilazane binders were found to enhance compaction and phase transition to $\beta-\mathrm{Si}_{3} \mathrm{~N}_{4}$ when used in the processing of $\alpha-\mathrm{Si}_{3} \mathrm{~N}_{4}$ [46]. Polyhydromethylsilazane-derived silicon carbonitride matrices provided greater oxidation resistance in composites with carbon fibres than the perhydropolysilazane-derived ones described in section $3.1[48,72]$. Ceraset-derived silicon carbonitride composites with carbon nanotubes were found to exhibit a weak ferromagnetic-like behaviour due to defects and inclusions in the nanotubes caused by the pyrolysis process [98]. Bakumov et al produced silver nanoparticle-silicon carbonitride composites as bulk samples and films, and found them to be effective antibacterial surfaces against Escherichia coli and Staphylococcus aureus, suggesting medical and food industry applications [92].

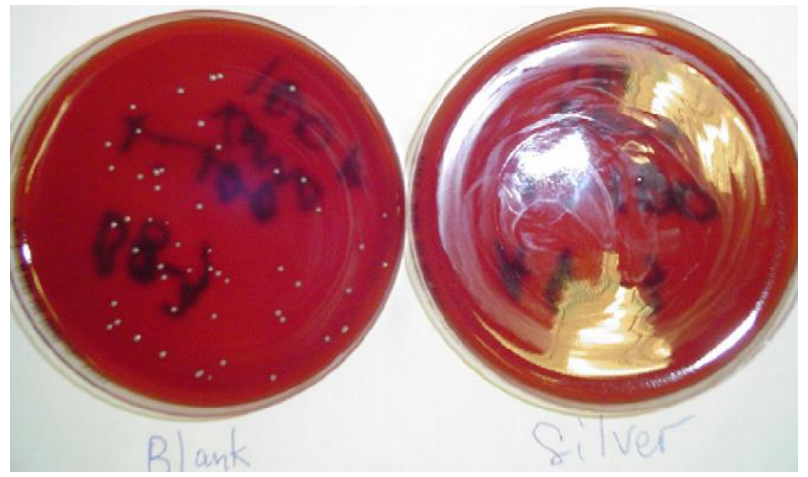

Figure 8: Photograph of two agar plates in contact with Staphylococcus aureus solutions. The reference sample on the left shows growth of bacterial colonies while the right, which also contains a silver-silicon carbonitride composite, is free from colonies. Reproduced with kind permission from [92]. 
The DC conductivity of silicon carbonitride prepared from polyhydromethylsilazane can be controlled across 15 orders of magnitude by varying firing time, temperature and atmosphere [119]. In the amorphous phase the conductivity was attributed to the tunnelling of large polarons, whereas after crystallisation n-type conduction in the nitrogen-doped $\mathrm{SiC}$ phase dominated. Variation of the amount of dicumyl peroxide thermal initiator added to Ceraset polysilazane in silicon carbonitride formation resulted in a change in conductivity, with conductivity increasing and evidence for a percolation conductivity mechanism when the free carbon content is higher [96]. The strong microwave absorption behaviour and the dielectric constant of porous silicon carbonitride were found to increase on crystallisation of $\mathrm{Si}_{3} \mathrm{~N}_{4}$ and $\mathrm{SiC}$ [103]. Thin, amorphous silicon carbonitride films can be used as hydrogen sensors due to a conductivity change on exposure to the gas [104].

Microporous SiCN composites with surface areas of $190-300 \mathrm{~m}^{2} \mathrm{~g}^{-1}$ can be produced by heating polyhydromethylsilazane with a $\mu \mathrm{m}$-sized $\mathrm{Si}_{3} \mathrm{~N}_{4}, \mathrm{SiC}$ or AIN filler in He at a very slow ramp rate, or even higher surface areas of $270-340 \mathrm{~m}^{2} \mathrm{~g}^{-1}$ using ammonia without the filler [66]. Presumably the ammonia increases the degree of crosslinking of the structure so that the structure can stabilise the pores as they form with gas loss. Bradley et al used microporous solids produced similarly but at lower temperature as base catalysts, utilising the surface imide groups to conduct Knoevenagel condensation reactions [68]. Tsubaki et al were able to vary the average pore size in SiCN compacts produced using polyhydromethylsilazane and an $\mathrm{Si}_{3} \mathrm{~N}_{4}$ filler between 1 and $1000 \mathrm{~nm}$ [67].

Sung et al demonstrated the production of macroporous silicon carbonitride structures templated around silica beads in channels using the Ceraset polyvinylsilazane (Fig. 9) [90]. Unlike oxide equivalents these were stable $>800^{\circ} \mathrm{C}$, where fuel reforming can take place without coking, so are suitable for catalyst supports for this process. Macroporous foams have been made from the same polymer using polymethylmethacrylate beads or a blowing agent to define the pore structure [99], or using polyethylene beads as the template [105]. Lamellar and cylindrical mesoporous structures have also been produced with a polyethylene oxide block copolymer [95]. Yan et al showed that a polyvinylsilazane could be infiltrated into mesoporous carbons and pyrolyzed to produce hexagonal or cubic (Fig. 9) ordered mesoporous silicon carbonitrides that were stable in air at $1000^{\circ} \mathrm{C}$ and had surface areas up to $472 \mathrm{~m}^{2} \mathrm{~g}^{-1}$ [93].
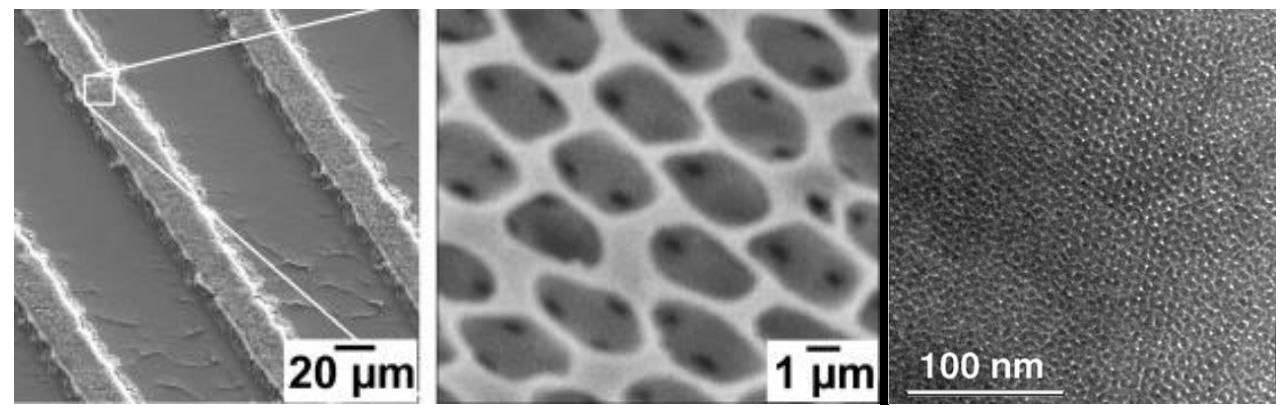

Figure 9: Macroporous silicon carbonitride microchannels produced as catalyst supports for high temperature fuel reforming (left and centre), and an ordered mesoporous la3d silicon carbonitride produced by casting into a carbon template (right). Reproduced with kind permission from [90,93].

Early studies of silicon carbonitride in lithium battery negative electrodes mixed a polyvinylsilazane with graphite powder and fired to achieve a composite that delivered a reversible capacity of 474

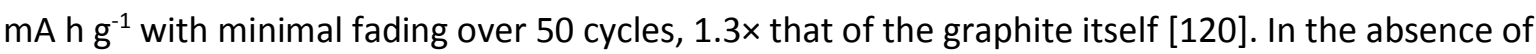
graphite addition divinylbenzene cross-linking of the polymer prior to pyrolysis was found to improve capacity whilst maintaining the good cyling behaviour, and the higher capacity was attributed to the larger carbon content of the ceramic [121]. Intentionally increasing the carbon 
content by preparing a polyphenylvinylsilazane polymer confirmed this finding [107], and using this approach capacities up to $618 \mathrm{~mA} \mathrm{~h} \mathrm{~g}^{-1}$ after 134 charge/discharge cycles have been achieved [122]. The dependence of the activity of these phases on carbon content, which is much more pronounced than in silicon oxycarbides, has been linked to the lack of reactivity of the Si-N bonds with lithium [123]. Incorporation of a silicon carbonitride into a porous carbon network using a polysilazane polymer has been shown to improve cycling capability relative to the carbon itself whilst maintaining a similar overall specific capacity [124]. Composites containing nanocrystalline lithium silicon nitride, and hence offering the possibility of using a non-lithiated positive electrode material, could be produced by lithiation of the polymer with BuLi before pyrolysis [125].

\subsection{Preceramic polymers with a Si-C-N backbone}

In polysilazane-based preceramics carbon can be introduced via substituent groups, and as crosslinking occurs through reactions of alkyl or vinyl groups these crosslinks can involve formation of Si(C) ${ }_{n}$-Si bonds. However, carbon can also be incorporated directly into the polymer chain itself. For example ammonolysis of bis(dichloroalkylsilyl)ethane leads to a polysilazane incorporating ethyl groups that has been used as the binder in production of $\mathrm{Si}_{3} \mathrm{~N}_{4} / \mathrm{SiC}$ composites from $\mathrm{Si}_{3} \mathrm{~N}_{4}$ powder [126] and also with $\mathrm{BN}, \mathrm{ZrO}_{2}$ or glass powder filler to produce composite coatings with hardness values up to $13 \mathrm{GPa}[51]$ :

$$
n \mathrm{Cl}_{2} \mathrm{RSi}\left(\mathrm{CH}_{2}\right)_{2} \mathrm{SiCl}_{2} \mathrm{R}+6 n \mathrm{NH}_{3} \rightarrow\left[\mathrm{EtSi}\left(\mathrm{CH}_{2}\right)_{2} \mathrm{SiEt}(\mathrm{NH})_{2}\right]_{n}+4 n \mathrm{NH}_{4} \mathrm{Cl}(\mathrm{R}=\mathrm{Me} \text { or Et })
$$

Su et al incorporated vinyl groups into a similar polymer that could be cross-linked with a radical initiator at $80^{\circ} \mathrm{C}$ by condensing ethylenediamine with vinylmethyldichlorosilane and methyldichlorosilane [127]. The resulting ceramics were found to be surprisingly rich in $\mathrm{SiN}_{4}$ sites, which the authors attributed to facile $\mathrm{C}-\mathrm{N}$ bond cleavage and loss of organic components below 600 ${ }^{\circ} \mathrm{C}$. Higher $\mathrm{C}$ contents in $\mathrm{Si}_{3} \mathrm{~N}_{4} / \mathrm{SiC}$ composite ceramics were achieved by Wang et al using a polymer with phenyl linkers and alkynyl end groups that again could be used for cross-linking (Fig. 10) [128].
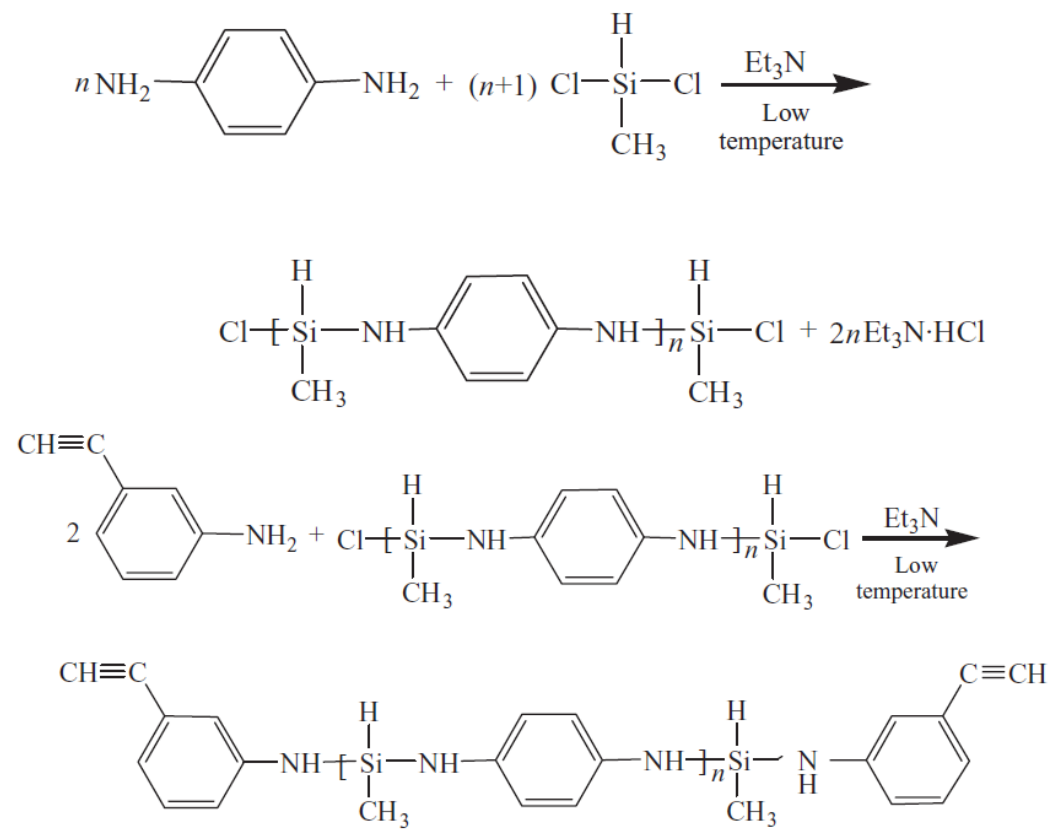

$+2 \mathrm{nEt}{ }_{3} \mathrm{~N} \cdot \mathrm{HCl}$

Figure 10: Synthesis route to a preceramic polymer for $\mathrm{Si}_{3} \mathrm{~N}_{4} / \mathrm{SiC}$ composites with phenyl linkers. Reproduced with kind permission from [128]. 
Use of polysilylcarbodiimides as preceramic and sol-gel precursors to silicon carbonitrides was reviewed by Riedel et al in 1998 [129] and 2006 [12]. Similarly to the polysilazanes, polydialkylsilylcarbodiimides can be produced by reaction of dialkyldichlorosilanes with cyanamide in pyridine solution:

$n \mathrm{MeRSiCl}_{2}+n \mathrm{H}_{2} \mathrm{NCN}+2 n \mathrm{Py} \rightarrow\left[\mathrm{MeRSiNCN}_{n}+2 n \mathrm{Py} \cdot \mathrm{HCl}(\mathrm{R}=\right.$ organic group or $\mathrm{H} ; \mathrm{Py}=$ pyridine $)$

Silver(I) carbodiimide and bis(trimethylsilyl)carbodiimide are good alternatives to cyanamide and the polymers can also be produced by reaction of polyorganosilazanes with cyanoguanidine (typically with pyridine still present in a catalytic role):

$$
\begin{gathered}
n \mathrm{MeRSiCl}_{2}+n \mathrm{Ag}_{2} \mathrm{NCN} \rightarrow[\mathrm{MeRSiNCN}]_{n}+2 n \mathrm{AgCl} \\
n \mathrm{MeRSiCl}_{2}+2 n \mathrm{Me}_{3} \mathrm{SiNCN} \rightarrow[\mathrm{MeRSiNCN}]_{n}+2 n \mathrm{Me}_{3} \mathrm{SiCl} \\
{\left[\mathrm{RR}^{\prime} \mathrm{SiNH}\right]_{n}+{ }^{n} / 2\left(\mathrm{H}_{2} \mathrm{NCN}\right)_{2} \rightarrow\left[\mathrm{RR}^{\prime} \mathrm{SiNCN}\right]_{n}+n \mathrm{NH}_{3}}
\end{gathered}
$$

The latter two options have the advantage of avoiding the salt by-products that are difficult to remove from the polymer.

Pyrolysis of [MeSi $\left.(\mathrm{NCN})_{1.5}\right]_{n}$ in argon resulted in amorphous ceramics up to $1400{ }^{\circ} \mathrm{C}$ [130]. The amorphous ceramic is found to be just a little more thermodynamically stable than the crystallised binary phases up to $1100{ }^{\circ} \mathrm{C}$ [131]. The phase diagram in Fig. 11 shows the loss of carbon at temperatures up to $800^{\circ} \mathrm{C}$ and TGA-MS studies showed this to be due to loss of methane and acetonitrile [130]. NMR studies showed that loss of methyl groups occurs at the lowest temperatures, leaving much of the carbodiimide network intact. Nitrogen is lost above $800{ }^{\circ} \mathrm{C}$ and in the temperature range up to $1200^{\circ} \mathrm{C}$ the amorphous material becomes almost fully segregated into $\mathrm{Si}_{3} \mathrm{~N}_{4}$ and carbon, hence in Fig. 11 it's composition is close to the $\mathrm{Si}_{3} \mathrm{~N}_{4}-\mathrm{C}$ tie-line. This phase segregation has been related to the lower packing efficiency of a mixed $\mathrm{SiN}_{x} \mathrm{C}_{y}$ network vs $\mathrm{SiN}_{4}$ tetrahedra [132]. The $\mathrm{Si}_{3} \mathrm{~N}_{4} / \mathrm{C}$ composition at this point means that the subsequent crystallisation to $\mathrm{Si}_{3} \mathrm{~N}_{4}$ and $\mathrm{SiC}$ must be a carbothermal reduction process with further loss of nitrogen. During crystallisation the composition of these polymers moves to the $\mathrm{SiC}-\mathrm{Si}_{3} \mathrm{~N}_{4}$ tie-line (Fig. 11) with the position on that line dependent on the composition of the polymer prior to crystallisation [133]. Crystallisation is found to start with the formation of small $\mathrm{Si}_{3} \mathrm{~N}_{4}$ nuclei $(\sim 2 \mathrm{~nm})$ at around $1400{ }^{\circ} \mathrm{C}$ [134]. 

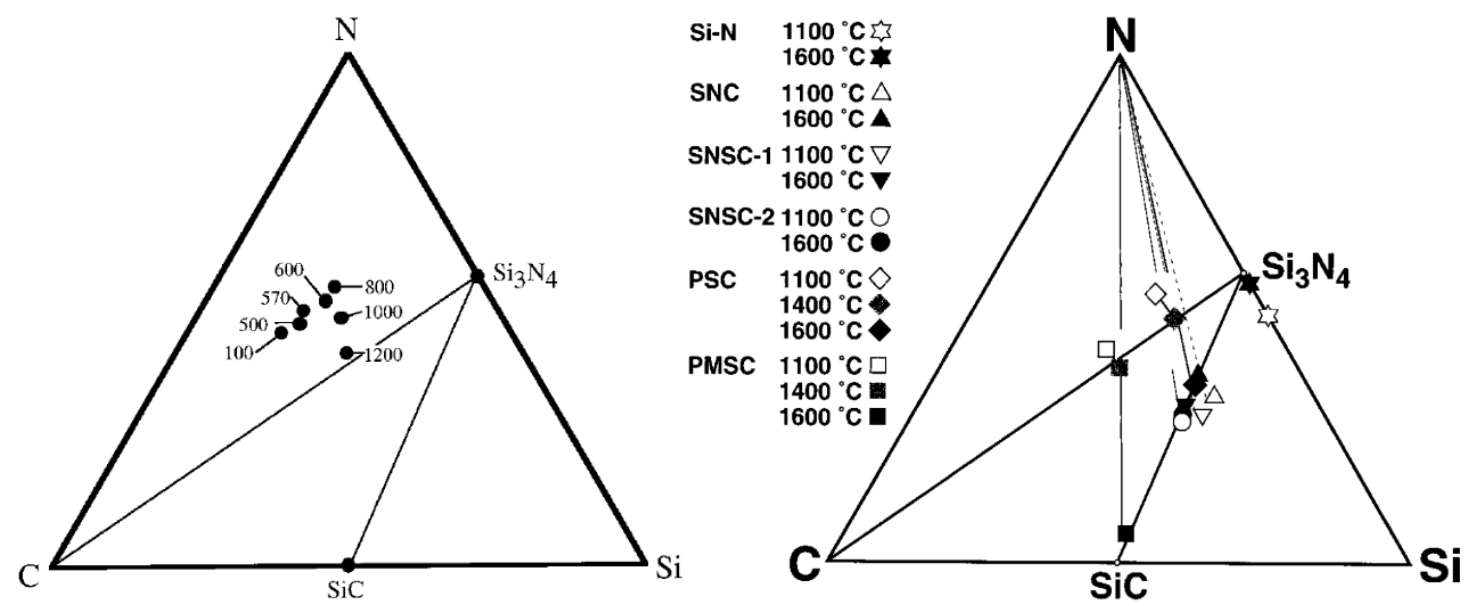

Figure 11: Silicon carbonitride compositions obtained during the decomposition of $\left[\mathrm{MeSi}(\mathrm{NCN})_{1.5}\right]_{n}$ in argon at temperatures as indicated (left); composition changes of various preceramic-derived polymers during crystallisation (right), where ceramics are based on $\left[\mathrm{H}_{2} \mathrm{SiNH}\right]_{n}(\mathrm{Si}-\mathrm{N}),[\mathrm{MeHSiNH}]_{n}(\mathrm{SNC}),\left[\mathrm{H}_{2} \mathrm{SiNH}\right]_{n} /\left[\mathrm{MeHSiCH}_{2}\right]_{n}$ mixtures $(\mathrm{SNSC}),\left[\mathrm{Si}(\mathrm{NCN})_{2}\right]_{n}(\mathrm{PSC})$ or $\left[\mathrm{MeSi}(\mathrm{NCN})_{1.5}\right]_{n}(\mathrm{PMSC})$. Reproduced with kind permission from $[130,133]$.

Incorporation of phenyl substituents onto the polymer can produce amorphous ceramics that are sufficiently carbon rich to result in $\mathrm{SiC}-\mathrm{C}$ composites after complete crystallisation, i.e. the carbothermal reduction results in complete loss of nitrogen [135]. However, these carbon-rich phases also exhibited higher crystallisation temperatures in some cases as the $\mathrm{Si}_{3} \mathrm{~N}_{4}$ domains became isolated within the carbon matrix, and some compositions close to the $\mathrm{Si}_{3} \mathrm{~N}_{4}-\mathrm{C}$ tie-line were obtained even at very high temperatures. The stability has been attributed to mixed bonding between $\mathrm{Si}, \mathrm{N}$ and $C$ atoms at the boundaries between the nanodomains [136]. The gas loss during carbothermal reduction has been found to produce ceramics with surface areas up to $568 \mathrm{~m}^{2} \mathrm{~g}^{-1}$ and tuneable porosity [137]. These samples were mainly microporous but adjustment of the conditions could raise the pore size to $\sim 4 \mathrm{~nm}$. Silicon carbonitride films based on carbodiimide polymers were found to be softer and less stiff where phenyl substituents were present compared with methyl groups, and this was attributed to the higher carbon content of these films [138].

In lithium battery applications the use of pre-ceramic based silicon carbonitride materials as negative electrodes has been envisaged to provide materials that can avoid degradation such as that deriving from exfoliation of graphitic carbons [139]. It has already been noted in section 3.2 that higher carbon contents have been related to higher capacities [121], and hence polymers with carbon in the backbone could provide higher capacity materials. Silicon carbonitrides based on polyphenylvinylsilylcarbodiimide had capacities of up to $392 \mathrm{~mA} \mathrm{~h} \mathrm{~g}^{-1}$ and could be cycled reversibly with no conductivity additive $[139,140]$. A study into the effect of different crosslinking methods showed that ceramics derived from [PhViSiNCN $]_{n}$ had very high capacity but this faded rapidly, whereas those based on $\left[\mathrm{PhSi}(\mathrm{NCN})_{1.5}\right]_{n}$, with more crosslinking, made up for a lower initial capacity by providing more reversible capacity $\left(420 \mathrm{~mA} \mathrm{~h} \mathrm{~g}^{-1}\right)$ after cycling (Fig. 12) [122]. A detailed NMR study showed that segregated carbon phases within the matrix were responsible for lithium storage, but that both $s p^{2}$ and $s p^{3}$ carbon sites were involved so this is not just utilisation of a graphitic content [107]. 


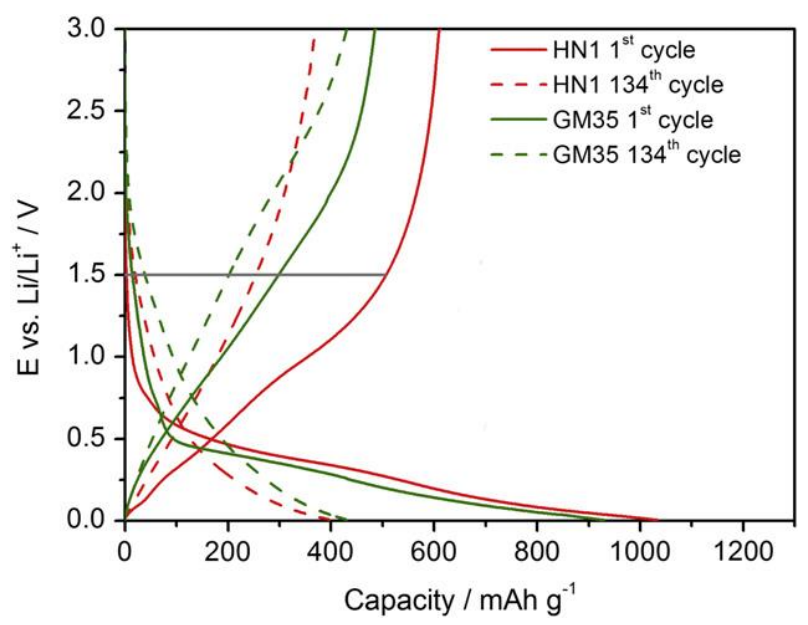

Figure 12: Charge-discharge curves (rate: $\mathrm{C} / 20$ ) for silicon carbonitride ceramics based on [PhViSiNCN] $\mathrm{n}(\mathrm{HN} 1)$ and $\left[\mathrm{PhSi}(\mathrm{NCN})_{1.5}\right]_{n}(\mathrm{GM} 35)$. Reproduced with kind permission from [122].

\subsection{Preceramic polymer routes to silicon boron (carbo)nitrides}

Quaternary Si-B-C-N ceramics can exhibit exceptional high temperature properties outstripping those of the binary and ternary systems. For example, $\mathrm{SiBN}_{3} \mathrm{C}$ remains amorphous to around $1900{ }^{\circ} \mathrm{C}$ and can used in air at temperatures up to $1600^{\circ} \mathrm{C}$ as a thin silica layer passivates the surface and the boron content reduces the amount of cation diffusion [141]. This material can be produced from pyrolysis in nitrogen of a polymer derived from $\mathrm{Cl}_{3} \mathrm{SiNHBCl}_{2}$ and $\mathrm{MeNH}_{2}$ (Fig. 13a), and the resulting intimate distribution of the three cations is critical to the properties of the resulting amorphous ceramic material. A scalable route to $\mathrm{Cl}_{3} \mathrm{SiNHBCl}_{2}$ was developed with preceramic applications in mind [142]. Preceramic routes to these materials have been reviewed previously [12-14,141]. These include the hydroboration of a vinyl group on a chlorosilane before polymerisation with ammonia to produce a polysilazane with boron cross-links (Fig. 13b) and reactions of borazine with silylamides to produce a polyborazine polymer cross-linked with silicon-containing groups (Fig. 13c). A pre-formed polyorganosilazane can also be reacted with borazine or tris(dimethylamino)borane to produce boron-containing side-groups, or the hydroboration reaction shown in Fig. 13b can be applied to vinyl side groups on a polysilazane polymer. Similar polymers have also been obtained by coammonolysis of $\mathrm{Me}_{2} \mathrm{SiCl}_{2}$ or $\mathrm{EtHSiCl}_{2}$ with $\mathrm{BCl}_{3}$ [143]. Much of this chemistry can also be applied with carbodiimide connecting groups in place of imide [144]. 
(a)

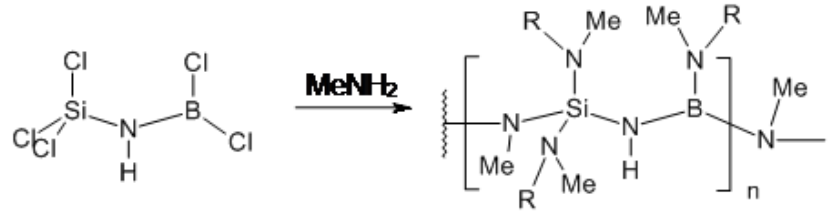

$(\mathrm{R}=\mathrm{H}$ or link to another $\mathrm{Si}$ or $\mathrm{B})$

(b)

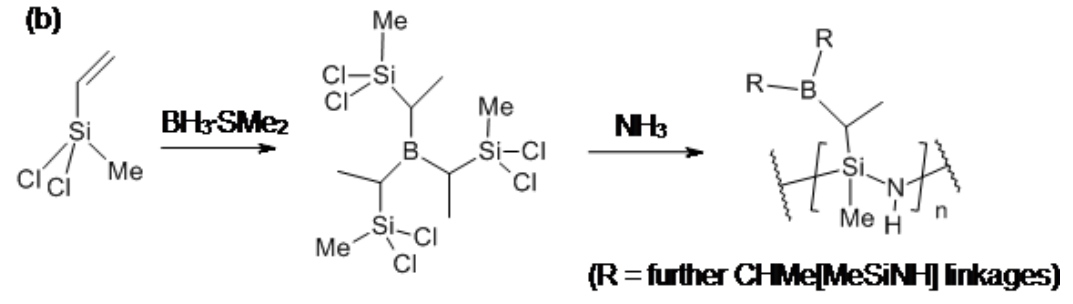

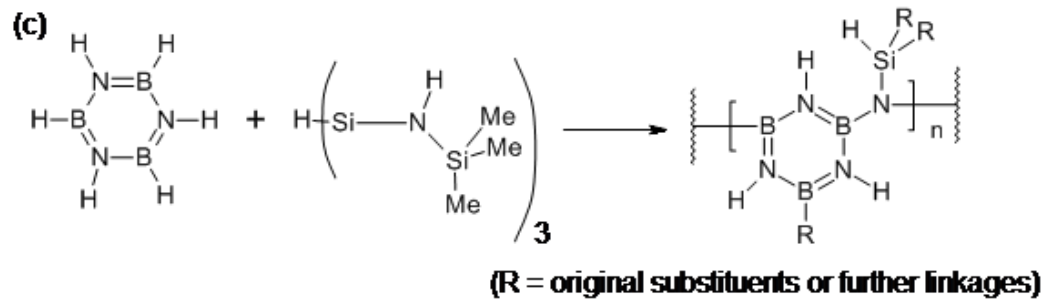

Figure 13: Key synthetic approaches to the synthesis of polymers suitable as precursors to Si-B-C-N materials [12-14,141].

A polymer produced by cross-linking of perhydropolysilazane with $\mathrm{BMe}_{3}$ decomposed with loss of hydrogen from about $400{ }^{\circ} \mathrm{C}$ (not complete at $1000^{\circ} \mathrm{C}$ ) with methane loss over a narrow temperature range around $600^{\circ} \mathrm{C}$ [145]. Carbon content dropped below $1 \%$ after this methane loss. $\mathrm{N}$-methylpolyborosilazane was found to decompose in three distinct steps en route to $\mathrm{SiBN}_{3} \mathrm{C}$, further condensation at $200-350{ }^{\circ} \mathrm{C}$, fragmentation at $580-600{ }^{\circ} \mathrm{C}$ (c.f. methane loss in the previous example) and elimination of residual hydrogen at $1000-1300{ }^{\circ} \mathrm{C}$ [146]. If ammonia is used transamination reactions become significant in the low temperature regime and alkylamide or alkylimide groups can be lost as amines [147]. NMR studies have shown that the behaviour of the system in the $600^{\circ} \mathrm{C}$ range where organic content can be lost by pyrolysis is critical to the structure of the amorphous ceramic: unsaturated carbon centres form but these remain connected into the network at this stage via bonds to nitrogen [148].

High resolution mapping by TEM shows that amorphous $\mathrm{Si}_{3} \mathrm{~B}_{3} \mathrm{~N}_{7}$ and $\mathrm{SiBN}_{3} \mathrm{C}$ have homogeneous distributions of the elements on a sub-nm scale, suggesting that the formation of inhomogeneities on this scale occurs during the crystallisation process [149]. These phases consist entirely of trigonal $\mathrm{BN}_{3}$ and tetrahedral $\mathrm{SiN}_{4}$ units, although on the shorter length scale probed by NMR some clustering of carbon sites was observed $[150,151]$. NMR studies on the pyrolysis of other polymer systems have shown that local formation of $s p^{2}$-like BN and amorphous SiCN regions can be detected with pyrolysis temperatures as low as $500^{\circ} \mathrm{C}$, and $s p^{2}$ carbon segregation occurs by $1050{ }^{\circ} \mathrm{C}[152,153]$. These findings have been confirmed with PDF work [154]. This segregated carbon has been linked directly to crack formation in ceramic bodies [155], and modelling of PDF data suggests its structure resembles glassy carbon [79]. At $1100{ }^{\circ} \mathrm{C}$ reactions start to occur between carbon and $\mathrm{BN}$, and the $\mathrm{BN}$ interfacial phase also starts to undergo reactions with the silicon carbonitride domains [156].

The process of nucleation and growth of segregated phases through the early stages described above and into crystallisation has been reviewed by Schmidt [157]. Crystalline SiC is found to nucleate first from an amorphous SiBCN ceramic at around $1400-1500{ }^{\circ} \mathrm{C}$, followed by $\mathrm{Si}_{3} \mathrm{~N}_{4}$ at 
around $1700^{\circ} \mathrm{C}$ [158]. Boron incorporation into silicon carbonitride by cross-linking a polyhydromethylsilazane with an undefined boron dialkylamide led to suppression of the crystallisation to $\mathrm{SiC}$ and $\mathrm{Si}_{3} \mathrm{~N}_{4}$ such that at $1800{ }^{\circ} \mathrm{C}$ the crystallite size is below $1800{ }^{\circ} \mathrm{C}$ [159]. This crystallite size reduction was attributed directly to a coating of turbostratic BN surrounding the crystallites. Phosphorus incorporation did not have the same effect. Presumably due to similar structures, BN was found to remain undetectable by diffraction to $1800^{\circ} \mathrm{C}$ in $\mathrm{SiBCN}$ fibres produced from borazine-modified perhydropolysilazane [160], and up to $2200{ }^{\circ} \mathrm{C}$ in some powder studies [161].

The oxidation resistance of $\mathrm{SiBCN}$ materials may be aided by the turbostratic BN phase that fills spaces between the particles, but the formation of a smooth silica passivating layer is also extremely important [162]. The role of the boron-containing phases was supported by variations in the amount of boron added in the route shown in Fig. 13b, where more boron led to higher oxidation temperatures [163]. Increasing the carbon content by incorporating methylene groups into the polymer backbone can lead to compositions such as $\mathrm{Si}_{3} \mathrm{~B}_{3} \mathrm{~N}_{7} \mathrm{C}_{5}$ and $\mathrm{Si}_{3} \mathrm{~B}_{3} \mathrm{~N}_{5} \mathrm{C}_{17}$ which can even resist pure oxygen at $1400^{\circ} \mathrm{C}$ [164]. These very high temperature resistant materials are difficult to analyse: typical combustion analysis approaches to $\mathrm{C}$ and $\mathrm{N}$ are hindered by the thermal stability and they are difficult to dissolve to measure $\mathrm{B}$ and Si. Mann et al explored a variety of digestion approaches combined with hot gas extraction techniques to analyse $\mathrm{SiBN}_{2.35} \mathrm{C}_{0.78}$ and were able to show close to $100 \%$ recovery of all components [165].

It has been mentioned above that it is at high temperature where silicon borocarbonitride ceramics often outperform the carbonitrides. For example, $\mathrm{Si}_{2} \mathrm{BC}_{3.4} \mathrm{~N}_{2}$ has a glass transition temperature $>1700$ ${ }^{\circ} \mathrm{C}$ and at $1550{ }^{\circ} \mathrm{C}$ has exceptional creep resistance and viscosity $10^{6} \times$ higher than that of fused silica [166]. Crack-free ceramic bodies may be produced by pressing $\mathrm{N}$-methylpolyborosilazane and then firing at $1400{ }^{\circ} \mathrm{C}$, some shrinkage is observed but the final $\mathrm{SiBN}_{3} \mathrm{C}$ object retains the shape of the pressed body [167]. Incorporation of less flexible elements such as borazine rings into the polymer has been shown to result in greater hardness and stiffness as they persist in the amorphous ceramics [168-170]. Smooth, dense ceramic films with air oxidation resistance up to $1400^{\circ} \mathrm{C}$ have been produced from a spin-coatable polymer produced as shown in Fig. $13 \mathrm{c}$ but using a cyclic [ViMeSiNH] silazane in place of the polyvinylsilazane [171]. Polymers with similar properties have been produced by the hydroboration of divinyldisilazane with various borazine derivatives [171]. Hyperbranched polymers achieved by reaction of $\mathrm{MeHSiCl}_{2}$ with $\mathrm{B}\left\{\mathrm{CH}(\mathrm{Me}) \mathrm{SiClMe}\left(\mathrm{SiMe}_{3}\right)\right\}_{3}$ proved to be particularly processable by melt and solution processes, with a ceramic yield of $>80 \%$ in production of $\mathrm{SiB}_{0.2} \mathrm{C}_{1.2} \mathrm{~N}_{0.4} \mathrm{O}_{0.1}[172]$.

Borazine-modified perhydropolysilazane polymers were particularly good for fibre formation as they could be melted and spun, but the borazine side-groups cross-link easily to other parts of the silazane polymer chain [160]. Ammonia cross-linking increased ceramic yield and allowed the formation of $\sim 12 \mu \mathrm{m}$ diameter amorphous fibres with fibre strength of 1.3-1.5 GPa after firing at $1600{ }^{\circ} \mathrm{C}$, dropping to $0.9 \mathrm{GPa}$ at $1700^{\circ} \mathrm{C}$ [173]. A variant of the synthesis route shown in Fig. $13 \mathrm{~b}$ has been used to provide the filler material in the production of sheets of SiBCN-carbon fibre composite which was stable for brief periods at $2000^{\circ} \mathrm{C}$ (Fig. 14) [174]. A polyborosilazane polymer produced from perhydropolysilazane and borazine was found to effectively wet silica fibres to produce ceramic composites [175] and these composites were found to have good ablation resistance and to be microwave transparent, suggesting radar window applications for vehicles re-entering the atmosphere from space [176]. 

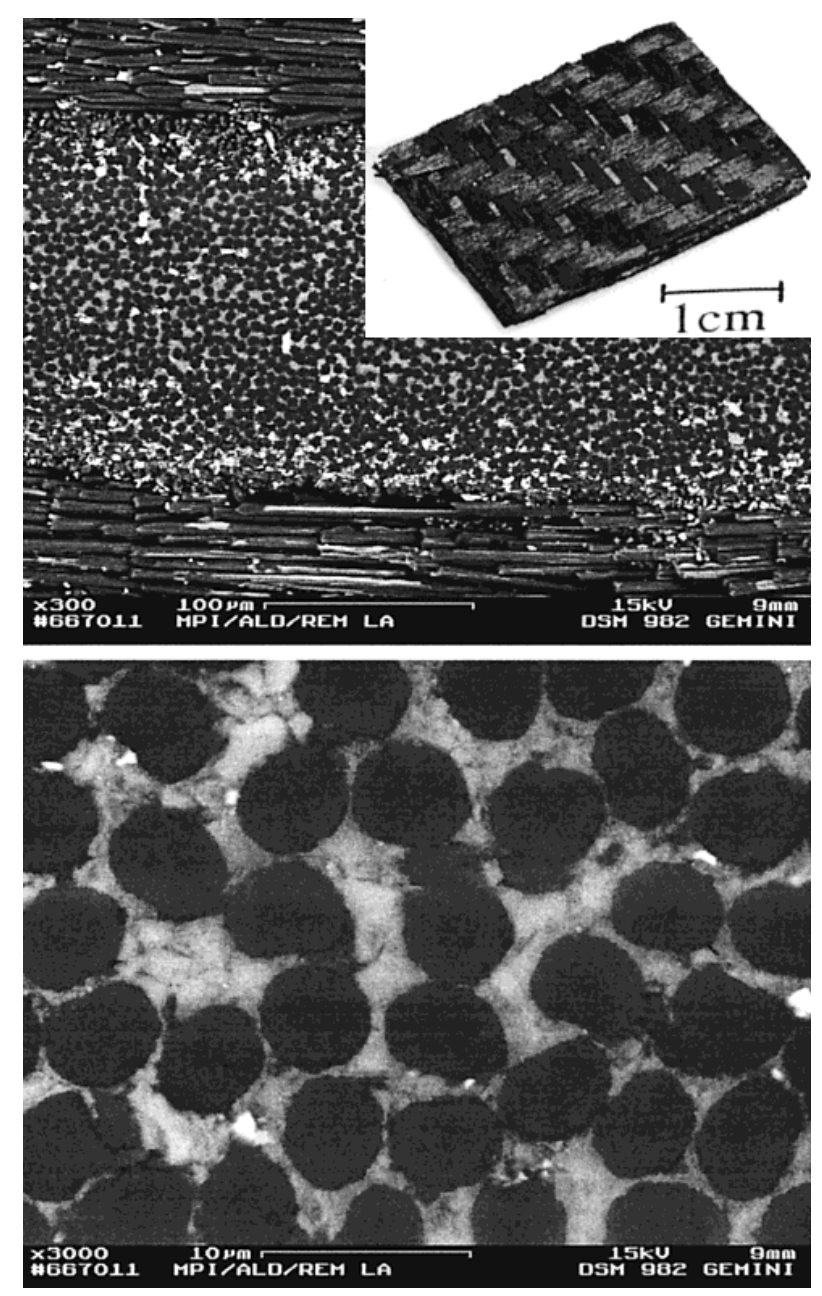

Figure 14: Cross-sections of carbon fibre-reinforced SiBCN ceramic and (inset) a photograph of the ceramic body showing the 8 -layer carbon weave. The 300x magnification image (top) has fibres directed left to right at the top and bottom of the image and perpendicular to the plane of the image in the central region. The 3000x image (bottom) shows the filling of the space between the fibres. Reproduced with kind permission from [174].

Porous structures can be produced by infiltration of liquid polymers around templates, e.g. Xing-Bin et al used a double nanocasting approach starting with SBA-15 silica to produce mesoporous $\mathrm{Si}_{3} \mathrm{BC}_{4.2} \mathrm{~N}_{3.5}$ with a surface area of $600 \mathrm{~m}^{2} \mathrm{~g}^{-1}$ and ordered $3.4 \mathrm{~nm}$ pores (Fig. 15) [177].
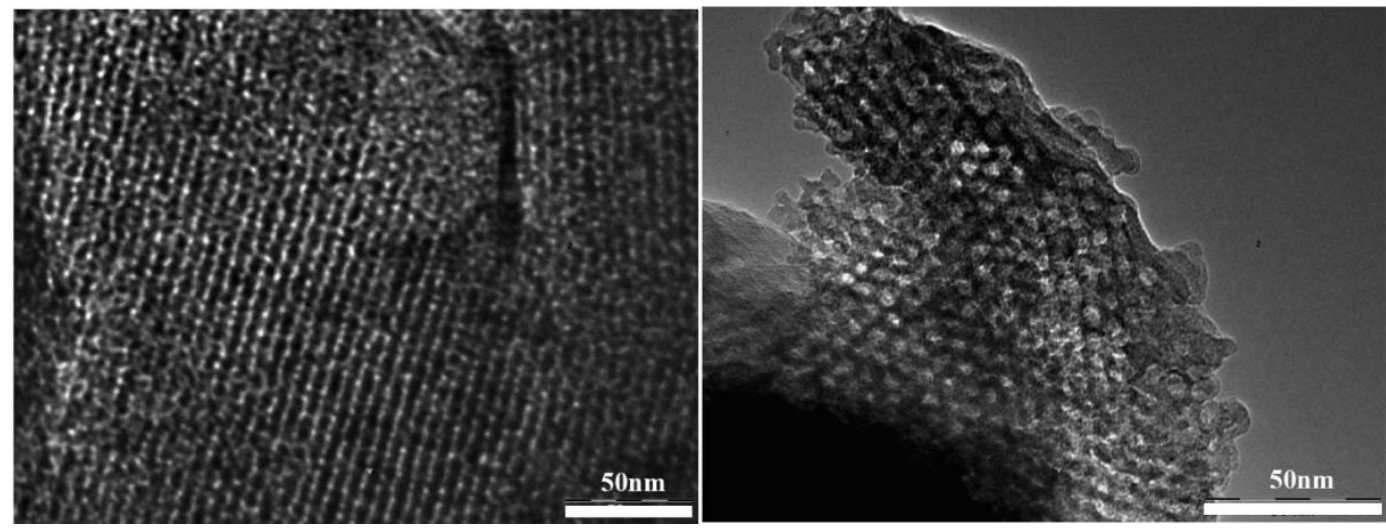

Figure 15: SBA-15-derived hexagonal mesoporous $\mathrm{Si}_{3} \mathrm{BC}_{4.2} \mathrm{~N}_{3.5}$ viewed perpendicular (left) and parallel (right) to the pore axes. Reproduced with kind permission from [177]. 
Ramakrishnan et al showed that $\mathrm{Si}_{2} \mathrm{BC}_{3.4} \mathrm{~N}_{2.3}$ had $p$-type semiconducting behaviour, in contrast to $\mathrm{Si}_{1.7} \mathrm{C}_{1.0} \mathrm{~N}_{1.6}$ which was made from a related polymer and had much lower conductivity [178]. They suggested that the passivation of surface states in this material could lead to a capability to make high temperature $p-n$ junctions. This higher conductivity has also been linked to an improved lithium battery electrode performance compared with silicon carbonitride, and SiBCN-carbon nanotube composites have been found to maintain $412 \mathrm{~mA} \mathrm{~h} \mathrm{~g}^{-1}$ capacity after 30 charge/discharge cycles [179]. A carbon-rich SiCN-BN composite showed exceptional stability, maintaining $401 \mathrm{~mA} \mathrm{~h} \mathrm{~g}^{-1}$ after 1000 cycles [180].

\subsection{Incorporation of other elements}

Similarly to boron, aluminium incorporation into amorphous silicon (boro)(carbo)nitrides is of interest to improve the oxygen tolerance of the parent material. Reaction of $\mathrm{Si}(\mathrm{NHMe})_{4}$ with an allane-NR 2 adduct yields a polymer that can be pyrolyzed to produce SiAIN nanocomposites [181]. Vinyl groups on a mixed methyl/vinyl/hydropolysilazane can also be cross-linked with $\left[\mathrm{Et}_{2} \mathrm{AINH}\right]_{3}$ to produce polymers that yield $\mathrm{SiC} / \mathrm{AIN}$ composites on firing at $1000^{\circ} \mathrm{C}$ [182]. Blending perhydropolysilazane and a polyethyliminoalane resulted in preceramics that also yielded crystalline AIN/SiC composites at $1600^{\circ} \mathrm{C}$ [183]. Templated production of amorphous mesoporous SiAICN ceramics from a similar bland and a carbon template provided robust supports for platinum nanoparticle catalysts [184]. Much better high temperature performance can be achieved with the aluminium analogue of the boron polymer shown in Fig. 13b, from which the resultant ceramics are amorphous up to $1400^{\circ} \mathrm{C}$ with similar local segregations of very small graphite-like, AIN and SiCN domains [185]. An amorphous SiAICN ceramic produced at $1000^{\circ} \mathrm{C}$ was found to be dense and suitable for the production of small scale fabricated structures using focussed ion beam milling (Fig. 16), suggesting possible MEMS applications [186].
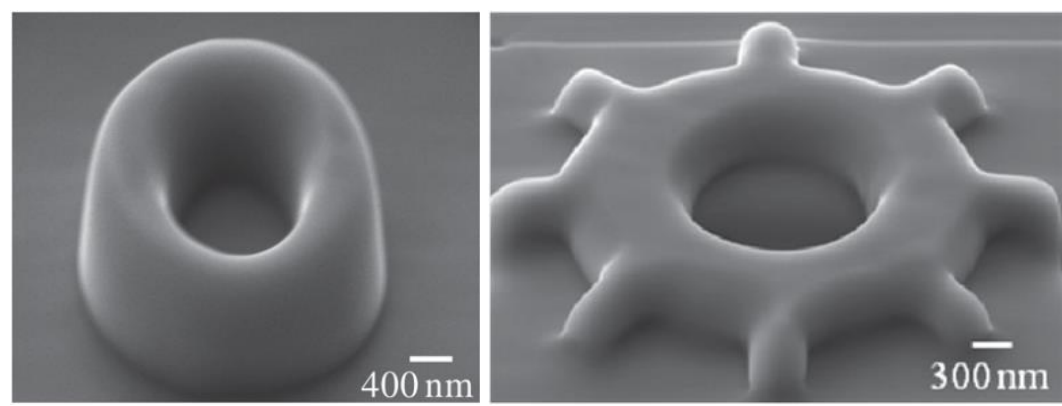

Figure 16: Nozzle (left) and gear (right) structures etched into a silicon aluminium carbonitride amorphous ceramic. Reproduced with kind permission from [186].

Reaction with perhydropolysilazane with $\mathrm{Ti}(\mathrm{OEt})_{4}$ or $\mathrm{Ti}\left(\mathrm{NMe}_{2}\right)_{4}$ resulted in amorphous phases from which small TiN nanoparticles crystallised from $\sim 1000{ }^{\circ} \mathrm{C}$ and in which the crystallisation of $\mathrm{Si}_{3} \mathrm{~N}_{4}$ (and $\mathrm{Si}_{2} \mathrm{~N}_{2} \mathrm{O}$ ) was suppressed below $\sim 1600{ }^{\circ} \mathrm{C}$ [187]. Later the same authors found that low levels of Ti doping from $\mathrm{Ti}\left(\mathrm{NMe}_{2}\right)_{4}$ could actually reduce the crystallisation temperature and $\alpha-\mathrm{Si}_{3} \mathrm{~N}_{4}$ was observed from $1000^{\circ} \mathrm{C}$ [188]. The difference appears to be that the bulk Ti-containing phase prevents crystalline nuclei growing much like the BN phases discussed in section 3.4, whereas small amounts of the easier to crystallise TiN provides nucleation sites for the silicon nitride. Formation of a titanium carbodiimide polymer with silicon-containing end group resulted in a similar partitioning of crystalline titanium carbonitride and small quantities of amorphous silicon carbonitride [189]. Zhou et al used $\mathrm{Hf}\left(\mathrm{NMe}_{2}\right)_{4}$ with perhydropolysilazane to produce nanocrystalline $\mathrm{HfN} /$ amorphous silicon nitride composites at $1100{ }^{\circ} \mathrm{C}$, with silicon nitride crystallising above $1300{ }^{\circ} \mathrm{C}$ [190]. They pointed out that the precursor formation is most likely to occur via transamination of the metal 
amide by the polysilazane imide groups. The same reaction applied to a commercial polyvinylsilazane, followed by hydroboration as shown in Fig. 13b, produced HfSiBCN ceramics that remained amorphous to $1300{ }^{\circ} \mathrm{C}$ before segregating during crystallisation [191], and which produced composites with carbon fibres with significantly better resistance to hydrothermal corrosion compared with silicon carbonitride [192]. Reaction of $\mathrm{CpZrCl}_{2}$ with a polyborosilazane polymer led to amorphous $\mathrm{ZrSiBCN}$ ceramics up to $1600{ }^{\circ} \mathrm{C}$, where phase segregation during crystallisation was again observed [193].

Iron and cobalt carbonyls react with a polyvinylsilazane to produce polymers that pyrolyse to composite ceramics containing metal silicide nanoparticles, although the magnetic behaviour of these was very similar to microparticles produced by incorporation of a metal filler into the polymer $[194,195]$. Pyrolysis of a polymer produced from iron(III) acetylacetonate and a similar polyvinylsilazane resulted in $\alpha$-Fe nanoparticles suspended in a silicon carbonitride matrix [196]. Polymer formation from metathesis of lithium silazane salts with $\mathrm{FeCl}_{3}$ led to materials in which iron nitrides could be maintained under ammonia pyrolysis conditions, or decomposed to Fe nanoparticles under nitrogen pyrolysis [197]. The polymers could be dip- or spin-coated and the resulting ceramics were strongly magnetised. Nickel polysilazane polymers produced from a polyvinylsilazane and trans-[bis(2-aminoethanol- $\mathrm{N}, \mathrm{O}$ )diacetato-nickel(II)] were superparamagnetic, indicating that small nickel nanoparticles were present even in the polymer [198]. Moderate temperature pyrolysis at $600{ }^{\circ} \mathrm{C}$ resulted in porous ceramics with up to $350 \mathrm{~m}^{2} \mathrm{~g}^{-1}$ surface area and the nanoparticles were credited with nucleating the formation of pores and of graphitic carbon. This material was later assessed for gas permeation membranes [199].

\section{Sol-gel routes to silicon nitride and related materials}

Sol-gel processing is distinct from the use of preceramic polymers in that the condensation reactions that produce a rigid network occur directly in the solution phase. A sol is a stable suspension of particles or polymer molecules in a liquid, and these can be built into a rigid network supporting the liquid, a gel, through further reactions that cross-link the structure [18]. There are significant overlaps with the polymer-based methods. Preceramic polymers need to maintain some solubility or meltability in order to be used to process controlled morphologies, or for ceramic bodies may be pressed as powders before firing. A high ceramic yield is typically a benefit. Sol-gel routes may drive condensation through solvent evaporation, especially in the "evaporation-condensation" route for films and fibres [22], but will always have some solvent present at the point when the structure becomes rigid. The loss of the solvent from the gel typically leads to porosity and lower density, and the porosity may be maintained through to the final material. Whilst polymer routes can be used to produce porous structures by templating or use of fillers as exemplified in a number of cases in section 3 , sol-gel processing excels in the production of porous and high surface area structures.

It should be noted that silicon nitride can be produced from conventional silica gels by high temperature carbothermal processes [200-202] including nanowire and nanotube structures [203206], but this requires temperatures above $1300{ }^{\circ} \mathrm{C}$. Direct sol-gel routes to silicon nitride and related materials typically develop a network structure through the formation of imide or carbodiimide linkages, in direct analogy with the irreversible formation of covalent oxide linkages in the hydrolytic sol-gel process ( $\mathrm{R}=\mathrm{H}$ or alkyl) [23]: 


$$
\begin{gathered}
n \mathrm{Si}(\mathrm{OR})_{4} \stackrel{\mathrm{H}_{2} \mathrm{O}}{\longrightarrow}\left[\mathrm{Si}(\mu-\mathrm{O})_{x}(\mathrm{OH})_{y}(\mathrm{OR})_{z}\right]_{n} \stackrel{\Delta}{\rightarrow} n \mathrm{SiO}_{2} \\
n \mathrm{Si}\left(\mathrm{NR}_{2}\right)_{4} \stackrel{\mathrm{NH}_{3}}{\longrightarrow}\left[\mathrm{Si}(\mu-\mathrm{NH})_{x}\left(\mathrm{NH}_{2}\right)_{y}\left(\mathrm{NR}_{2}\right)_{z}\right]_{n} \stackrel{\Delta}{\rightarrow} n / 3 " \mathrm{Si}_{3} N_{4} " \\
n \mathrm{Me}_{3} \mathrm{SiCl}_{3} \stackrel{\left(\mathrm{Me}_{3} \mathrm{Si}_{2} \mathrm{NCN}\right.}{\longrightarrow}\left[\mathrm{MeSi}(\mathrm{NCN})_{1.5}\right]_{n} \stackrel{\Delta}{\rightarrow} n \mathrm{SiC}_{x} \mathrm{~N}_{y}
\end{gathered}
$$

Control of the gel formation chemistry involves ensuring that the correct balance between formation of the condensing species and the condensation reaction reactions that consume these species is achieved, such that gelation occurs in the requisite manner, e.g. quickly in an evaporation-driven process but also evenly through the structure such that a strong continuous network forms that can survive further processing steps. During pyrolysis a number stages will occur and these may or may not involve an active gas environment such as $\mathrm{NH}_{3}$, and $\mathrm{Si}_{3} \mathrm{~N}_{4}$ is placed in quotation marks above as this is only achieved at very high temperatures under ammonia. There is a clear possibility that carbon will also be incorporated from any alkyl groups present in the precursor, and imide groups persist even at $1400^{\circ} \mathrm{C}$ in the amorphous material [207].

\subsection{Sol-gel processing from silicon amides and ammonia}

The first reports of sol-gel processing of silicon nitride using ammonia as the cross-linking agent were from Bradley and co-workers [208]. A mixed silicon dialkylamide-amide precursor was used to overcome the lack of reactivity of homoleptic dialkylamides, this could be cyclised with a triflic acid catalyst and then cross-linked with ammonia to form a rigid gel:

$$
\begin{gathered}
\mathrm{SiCl}_{4}+6 \mathrm{Me}_{2} \mathrm{NH} \rightarrow\left(\mathrm{Me}_{2} \mathrm{~N}\right)_{3} \mathrm{SiCl}+3 \mathrm{Me}_{2} \mathrm{NH} \cdot \mathrm{HCl} \\
\left(\mathrm{Me}_{2} \mathrm{~N}\right)_{3} \mathrm{SiCl} \stackrel{\mathrm{NH}_{3}, \mathrm{Et}_{2} \mathrm{O},-50^{\circ} \mathrm{C}}{\longrightarrow}\left(\mathrm{Me}_{2} \mathrm{~N}\right)_{3} \mathrm{SiNH} \\
\left(\mathrm{Me}_{2} \mathrm{~N}\right)_{3} \mathrm{SiNH} \stackrel{\mathrm{CF}_{3} \mathrm{SO}_{3} \mathrm{H},-50^{\circ} \mathrm{C}}{\longrightarrow}\left[\left(\mathrm{Me}_{2} \mathrm{~N}\right)_{2} \mathrm{SiNH}\right]_{3} \\
n / 3\left[\left(\mathrm{Me}_{2} \mathrm{~N}\right)_{2} \mathrm{SiNH}\right]_{3} \stackrel{\mathrm{CF}_{3} \mathrm{SO}_{3} \mathrm{H}, \mathrm{THF}, \mathrm{NH}_{3}}{\longrightarrow}\left[\mathrm{Si}(\mu-\mathrm{NH})_{x}\left(\mathrm{NH}_{2}\right)_{y}\left(\mathrm{NMe}_{2}\right)_{z}\right]_{n}
\end{gathered}
$$

Solvent removal from the gel in vacuo followed by ammonia treatment at $50^{\circ} \mathrm{C}$ resulted in a silicon imidonitride with surface area of $500 \mathrm{~m}^{2} \mathrm{~g}^{-1}$ containing imide and amide groups but no organic amide [208]. A variation of this process used formamide to cross-link the gel, resulting in silicon oxynitride glasses [209].

We have used a similar process based on $\mathrm{Si}(\mathrm{NHMe})_{4}$ and ammonia to produce silicon nitride precursors gels, although this process in harder to control. In order to prevent precipitation the ammonolysis was carried out at low temperature as with $\left[\left(\mathrm{Me}_{2} \mathrm{~N}\right)_{2} \mathrm{SiNH}\right]_{3}$, but in addition the amount of ammonia needed to be controlled and the triflic acid needed to be added as the preammonolysed sol was warming up. This procedure has been used to provide controlled gelation to yield monolithic gels [210] and in dip-coating to provide continuous films by evaporationcondensation [211]. Cheng et al suggested that the triflate anions, rather than the protons introduced from the acid, were important in the catalysis of the condensation process, probably by attacking silicon centres first then providing a good leaving group when they are attacked by amide groups on other silicon centres [212]. Use of ammonium triflate as the catalyst resulted in slower gelation (suggesting the acid may have some role), but allowed the process to be simplified by addition of the catalyst from the start of the reaction [207]:

$$
\mathrm{n} \mathrm{Si}(\mathrm{NHMe})_{4} \stackrel{\left[\mathrm{NH}_{4}\right]\left[\mathrm{CF}_{3} \mathrm{SO}_{3}\right], \mathrm{THF}, \mathrm{NH}_{3},-78^{\circ} \mathrm{C}}{\longrightarrow}\left[\mathrm{Si}(\mu-\mathrm{NH})_{x}\left(\mathrm{NH}_{2}\right)_{y}(\mathrm{NHMe})_{z}\right]_{n}
$$


It is still necessary to measure the quantity of ammonia, but the mixture can be assembled in a single reaction vessel and gelation occurs a period of time after the mixture warms to ambient temperature, with that period determined by the catalyst concentration [207]. This work showed that the triflate is incorporated and does result in some oxygen contamination, although this can be minimised by reducing its concentration to genuinely catalytic quantities (albeit with an increase in reaction time). Firing these gels at a variety of temperatures resulted in high surface area silicon nitride materials, with amide/imide content persisting even at $1400^{\circ} \mathrm{C}$. Diffraction and PDF studies (Fig. 17) showed that the structure varies little from $200-1200^{\circ} \mathrm{C}$, with the corner-linked tetrahedra of the $\mathrm{Si}_{3} \mathrm{~N}_{4}$ structure dominating and only the correlation length of the repeat structures changing significantly as the materials crystallised as $\alpha-\mathrm{Si}_{3} \mathrm{~N}_{4}$ at $1400{ }^{\circ} \mathrm{C}$.
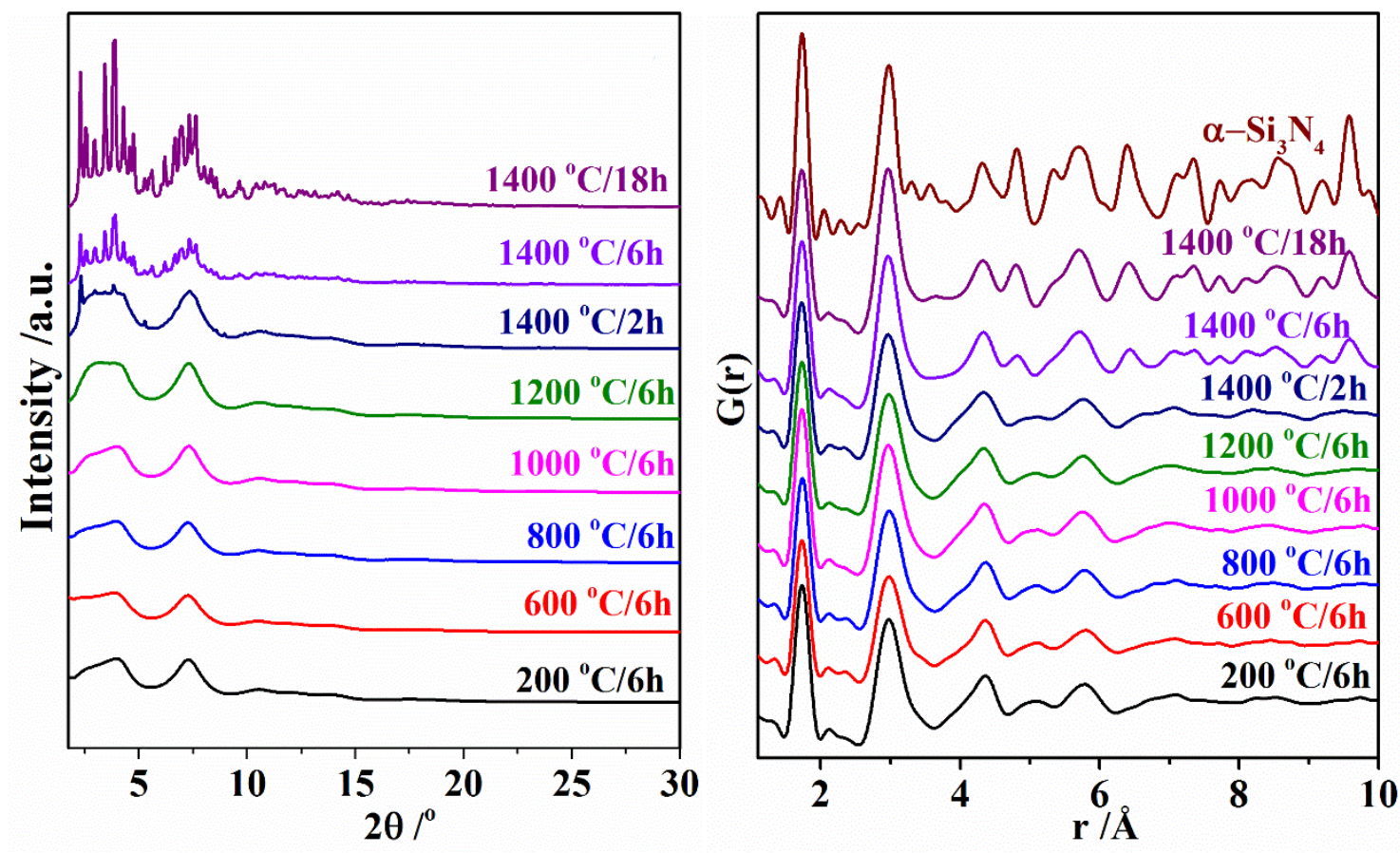

Figure 17: Total scattering intensity (left) and PDFs (right) of silicon (imido)nitride samples produced by heating $\mathrm{Si}(\mathrm{NHMe})_{4}$-derived gels in ammonia under conditions as shown. Calculated PDF for $\alpha-\mathrm{Si}_{3} \mathrm{~N}_{4}$ is shown top right. Reproduced with kind permission from [207].

The surface amide/imide groups on silicon imidonitride materials produced from gels cross-linked by, and fired under, ammonia can be used as base catalysts, for example in the Knoevenegal condensation of benzaldehyde with malonitrile to produce 1,1-dicyanophenylethylene using microporous silicon imidonitride $[68,213]$. Pyrolysis of gels based on $\left[\left(\mathrm{Me}_{2} \mathrm{~N}\right)_{2} \mathrm{SiNH}\right]_{3}$ under ammonia led to mesoporous silicon imidonitride with 3-4 $\mathrm{nm}$ pores and surface areas up to $983 \mathrm{~m}^{2} \mathrm{~g}^{-1}$ [214]. Larger pore sizes of $\sim 5.6 \mathrm{~nm}$ can be produced by templating the formation of silicon imidonitride with long chain amines [215]. Comparing this material with a microporous analogue, it was found that the larger surface area microporous material was more active in the alkylation of toluene with ethylene, but the alkylation of the larger styrene molecule only proceeded over the mesoporous catalyst, presumably because it didn't fit into the smaller pores. Both catalysts were effective in the isomerisation of hex-1-ene, but the larger 1-hexadecene was only isomerised in the mesoporous catalyst.

Porosity also has a number of applications beyond catalysis, and mesoporous silicon imidonitride films with 2-3 nm pores deposited from a [(Me $\left.\left.\mathrm{N}_{2}\right)_{2} \mathrm{SiNH}\right]_{3}$-derived sol onto macroporous substrates have been shown to make effective gas filtration membranes (Fig. 18) [216]. A gas sensor produced 
with this membrane was able to detect hydrogen, carbon monoxide and propane but excluded nitrogen dioxide. A recent patent also envisages using solid mesoporous bodies of silicon imidonitride as chromatography media for chemical separation [217]. Supercritical drying of $\mathrm{Si}(\mathrm{NHMe})_{4}$-derived gels with ammonia-saturated diethylamine resulted in robust monolithic aerogel bodies with little shrinkage relative to the wet gel (Fig. 18) [210]. The structure of the gel consisted of fibrils with a hierarchical network of larger ( $100 \mathrm{~nm})$ macropores and then further mesopores through the entire structure. Application of a similar drying procedure to a $\left[\left(\mathrm{Me}_{2} \mathrm{~N}\right)_{2} \mathrm{SiNH}\right]_{3}$-derived gel resulted in aerogels that had the "pearl necklace" morphology often seen in $\mathrm{SiO}_{2}$ aerogels with a much more open network of macropores (Fig. 18) but also a similar arrangement of mesopores within the spherical features [218].
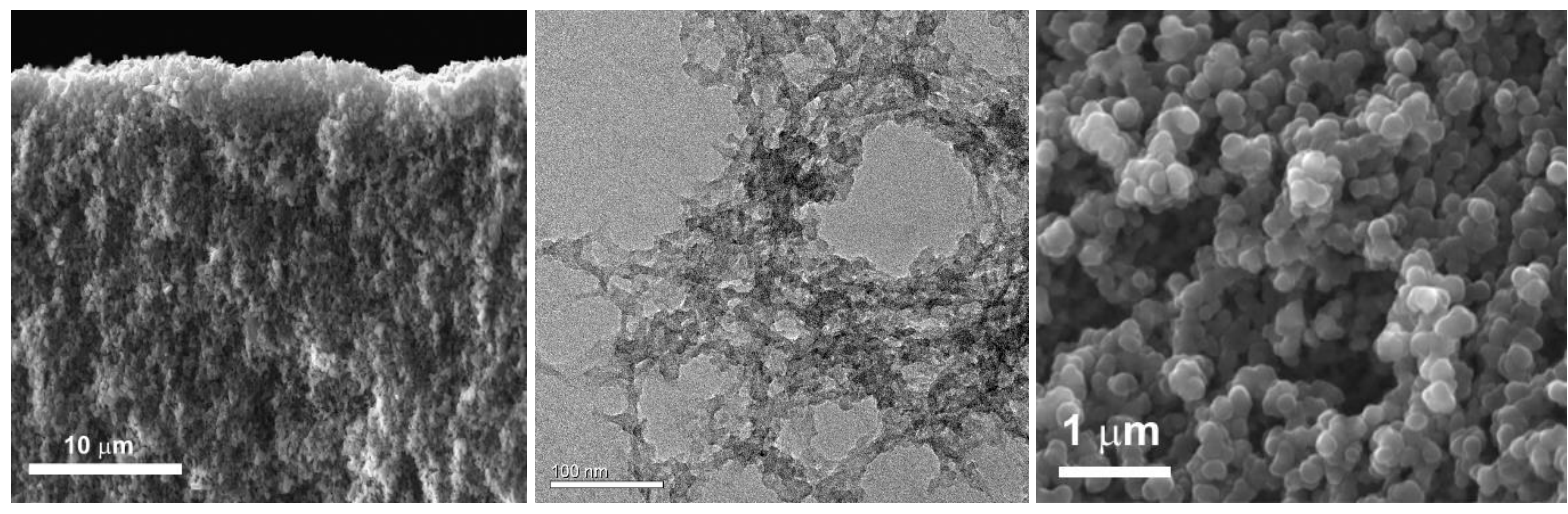

Figure 18: SEM image of a cross section of a silicon imidonitride membrane (left), TEM image of a Si(NHMe) $4_{4}$ derived aerogel (centre) and SEM image of a $\left[\left(\mathrm{Me}_{2} \mathrm{~N}\right)_{2} \mathrm{SiNH}\right]_{3}$-derived aerogel (right). Reproduced with kind permission from $[210,216,218]$.

It is also feasible to use the ammonia to produce a preceramic polymer then use a different crosslinker to produce the gel. Nguyen et al recently cross-linked perhydropolysilazane with divinylbenzene to produce gels that could be dried under supercritical $\mathrm{CO}_{2}$ to make aerogels then fired at $1000{ }^{\circ} \mathrm{C}$, retaining $150 \mathrm{~m}^{2} \mathrm{~g}^{-1}$ surface area in a hierarchical meso/microporous structure [219].

\subsection{Incorporation of other elements under ammonolytic sol-gel conditions}

Lithiation of $\left(\mathrm{Me}_{2} \mathrm{~N}\right)_{3} \mathrm{SiNH}_{2}$ followed by metathesis with $\mathrm{BCl}_{3}$ results in $\mathrm{B}\left(\mathrm{NHSi}\left(\mathrm{NMe}_{2}\right)_{3}\right)_{3}$, which can be gelled with ammonia under similar conditions to $\left[\left(\mathrm{Me}_{2} \mathrm{~N}\right)_{2} \mathrm{SiNH}_{3}[220,221]\right.$. Pyrolysis of this gel at $1000^{\circ} \mathrm{C}$ results in a mesoporous silicon boron imidonitride with a $1: 3$ ratio of $\mathrm{B}: \mathrm{Si}$. This ratio can be varied by substituting the $\mathrm{BCl}_{3}$ with borazines containing 2 or 3 chloride groups attached to boron, to yield gels with $3: 2$ or 1:1 ratio of B:Si and surface areas of 788 or $439 \mathrm{~m}^{2} \mathrm{~g}^{-1}$, respectively [222]. The THF adduct of $\mathrm{Al}\left(\mathrm{NHSi}\left(\mathrm{NMe}_{2}\right)_{3}\right)_{3}$ was used to form gels that pyrolyzed under ammonia to an amorphous ceramic with a 1:3 Al:Si ratio, contained $\mathrm{SiN}_{4}$ tetrahedra and a mixture of $\mathrm{AIN}_{4}, \mathrm{AIN}_{5}$ and AIN $_{6}$ groups [223]. The catalytic properties of these materials, in which the basicity would be expected to be modified relative to the silicon imidonitrides, do not appear to have been examined.

Reactions of transition metal amides with ammonia are usually poorly controlled, and a less reactive cross-linker such as a primary amine is necessary to achieve controlled sol-gel processing $[28,224,225]$. Löffelholz et al mixed boron, titanium, zirconium and tantalum dimethylamides with $\mathrm{Si}(\mathrm{NHMe})_{4}$ and achieved gelation by cross-linking with ammonia without a requirement for a catalyst $[226,227]$. The ammonolysis rate of the titanium amide was six times that of the silicon amide, but homogeneous gels were still obtained with a 1:1 ratio of silicon to the other element. The lack of a catalyst in these systems is in contrast to the low reactivity of $\mathrm{Si}(\mathrm{NHMe})_{4}$ by itself [228] and the 
controlled formation of gels is also in contrast to the behaviour of the metal amides themselves, which would precipitate under these conditions $[229,230]$. It seems that at these concentrations the condensation reactions must occur at rates that are intermediate between the poorly reactive silicon amide and the more reactive metal amides. Firing these mixed gels at $1000^{\circ} \mathrm{C}$ led to largely amorphous ceramics, but nanocrystalline metal nitrides and/or some $\alpha-\mathrm{Si}_{3} \mathrm{~N}_{4}$ grew from the matrix at $1500{ }^{\circ} \mathrm{C}$. It was possible to broaden the range of metals with which these mixed nitrides could be produced by making single source precursors through reactions of their chlorides with $(\mathrm{LiMeN})_{2} \mathrm{Si}\left(\mathrm{NMe}_{2}\right)_{2}[227]$.

The segregation of the metal to produce crystalline, nanoparticulate metal nitride phases supported on a high surface area silicon nitride is potentially very useful in heterogeneous catalysis, where a range of reactions could be carried out using the activity of the metal nitrides, possibly in some cases in conjunction with the base functionality of the imidonitride itself $[231,232]$. Typically this would involve reducing the catalyst loading to levels more comparable with other supported catalysts. At $10 \%$ loading $(\mathrm{M}: \mathrm{Si}=1: 10)$ gelation of $\mathrm{Ta}\left(\mathrm{NMe}_{2}\right)_{5}$ and $\mathrm{Si}(\mathrm{NHMe})_{4}$ do not gel, but introduction of triflic acid to catalyse the condensation reactions as discussed in section 4.1 allows the reactions to proceed [233]. Similarly this reaction produced an amorphous tantalum-silicon imidonitride at 1000 ${ }^{\circ} \mathrm{C}$, although $\mathrm{X}$-ray absorption fine structure studies showed that some crystalline nuclei of tantalum nitride too small to be observed by XRD were formed. With $\mathrm{Mo}\left(\mathrm{NMe}_{2}\right)_{4}$ phase segregation occurred and molybdenum nitride nanotubes grew at $1000{ }^{\circ} \mathrm{C}$. These studies point to a possibility of controlling the nanocrystal size on the silicon nitride support using the relative reactivity of the precursors and the firing temperature.
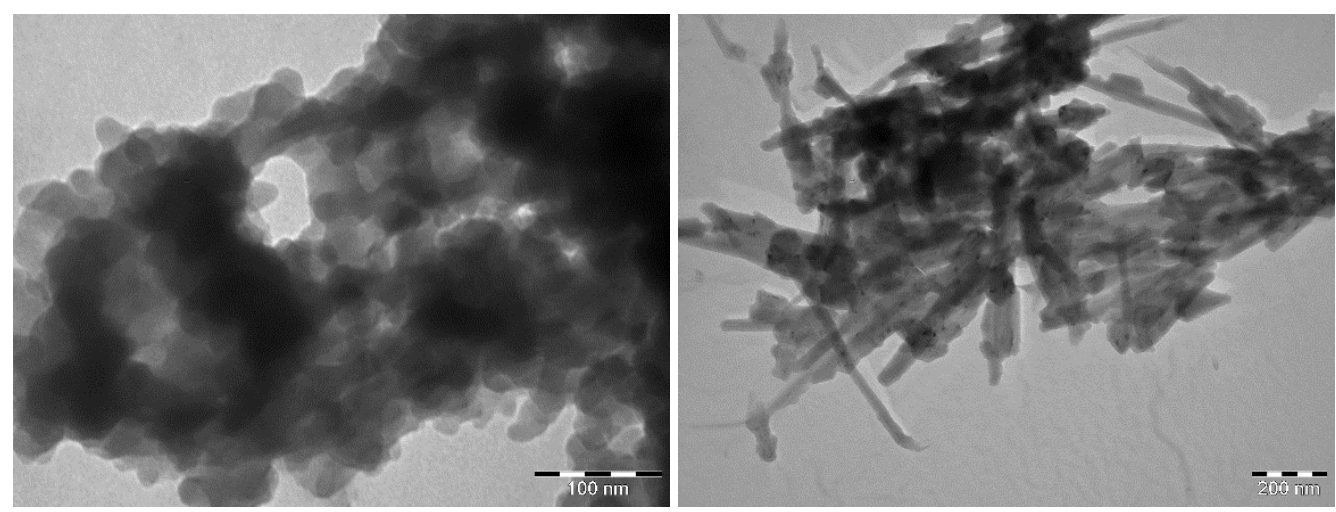

Figure 19: TEM images of amorphous tantalum silicon nitride (left) and molybdenum nitride nanotubes with amorphous silicon nitride particles (right) produced from ammonolysis of a 1:10 mixture of metal amide to $\mathrm{Si}(\mathrm{NHMe})_{4}$ followed by firing the gel in ammonia at $1000^{\circ} \mathrm{C}$. Reproduced with kind permission from [233].

An alternative approach to incorporation of the metal at the molecular stage is to preform the imidonitride gel and then react it with a metal source. Cheng et al reacted $\left[\left(\mathrm{Me}_{2} \mathrm{~N}\right)_{2} \mathrm{SiNH}\right]_{3}$-derived gels with $\mathrm{PdCl}_{2}$ and EXAFS showed the Pd coordination sphere to contain bonds to both $\mathrm{N}$ and $\mathrm{Cl}$ such that the polymer must be decorated with Pd [234]. Pyrolysis led to mesoporous structures with 5-12 $\mathrm{nm}$ or 15-25 nm pores, depending on pyrolysis conditions, and 5-20 nm Pd nanoparticles dispersed throughout the matrix. These were found to more active than crystalline $\mathrm{Si}_{3} \mathrm{~N}_{4}$ infiltrated with $\mathrm{Pd}$ nanoparticles in alkene isomerisation reactions and in the hydrogenation of alkenes and of cyclohexanone $[234,235]$.

\subsection{Silicon carbodiimide based sol-gel processing}

Pyridine-catalysed reactions of $\mathrm{MeSiCl}_{3}$ or $\mathrm{SiCl}_{4}$ with $\left(\mathrm{Me}_{3} \mathrm{Si}\right)_{2} \mathrm{CNC}$ yield polymers with three or four carbodiimide groups per silicon atom, which are inherently cross-linked and hence lack the solubility 
or meltability required for polymer processing methods to be applied [130]. The linear analogues produced from the alkylsilicon dichlorides, and the thermal phase behaviour of a range of compositions in this system including those under discussion here, are described in section 3.3. Solgel processing can be readily applied in this system since the formation of a 3-dimensionally linked gel is part of the process anyway. The time taken for a mixture to gel is variable with the concentration of the pyridine catalyst, but a few days at room temperature or a few hours at $90{ }^{\circ} \mathrm{C}$, where the removal of the $\mathrm{Me}_{3} \mathrm{SiCl}$ by-product by distillation is accelerated, is typical [236]. Even after gelation the polymeric species within the gel are still terminated by trimethylsilyl groups that are detectable by IR spectroscopy, and condensation reactions continue as the gels are aged [237]. Hence the appearance of the gels changes over time from transparent to turbid and then opaque (Fig. 20). These condensation reactions result in some shrinkage of the gel body, and further shrinkage during drying results in an overall change of $\sim 40 \%$. However monolithic gels can be obtained. Firing these leads to a composite of amorphous $\mathrm{Si}_{3} \mathrm{~N}_{4}$ and carbon [130], with crystallisation temperatures as high (depending on final composition) as $1500{ }^{\circ} \mathrm{C}$ for $\mathrm{Si}_{3} \mathrm{~N}_{4}$ and $1600{ }^{\circ} \mathrm{C}$ for SiC [133].
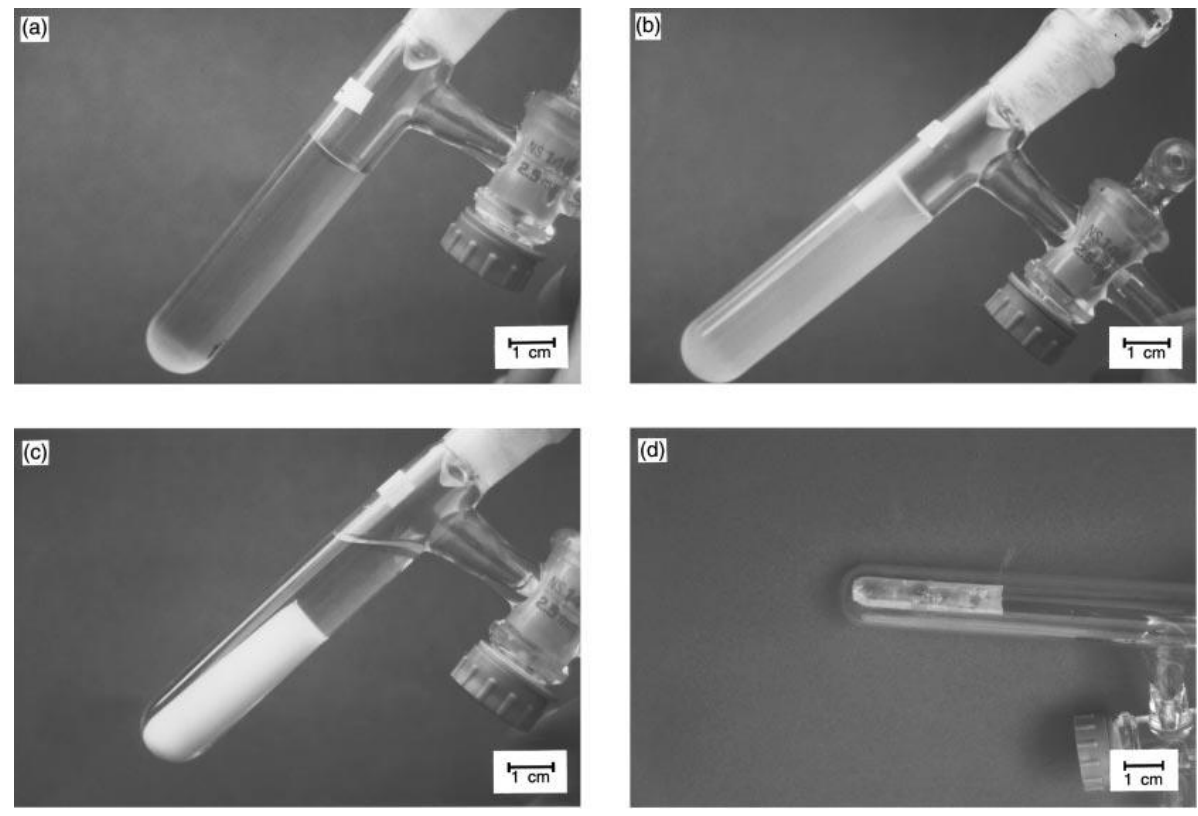

Figure 20: Appearance of a $\left[\mathrm{MeSi}(\mathrm{NCN})_{1.5}\right]_{n}$ gel immediately after gelation (a), after aging at $45^{\circ} \mathrm{C}$ for 5 days (b) or 50 days (c), and after evaporation of the liquid phases to yield a transparent xerogel (d). Reproduced with kind permission from [237].

An alternative route to $\left[\mathrm{Si}(\mathrm{NCN})_{2}\right]_{n}$ via the decomposition of the isocyanate in solution at high temperature catalysed by 1-phenyl-3-methyl-2- phospholene-1-oxide to form gels [238]:

$$
n \mathrm{Si}(\mathrm{NCO})_{4} \stackrel{\Delta}{\rightarrow}\left[\mathrm{Si}(\mathrm{NCN})_{2}\right]_{n}+2 n \mathrm{CO}_{2}
$$

This route was developed with the aim of providing a hydrogen-free polymer that could crystallise more readily, but the lack of a by-product that would need to be removed was also mentioned as an advantage [238]. The thermal decomposition behaviour was similar to that of $\left[\mathrm{MeSi}(\mathrm{NCN})_{1.5}\right]_{n}$, in that carbon and an amorphous silicon (carbo)nitride phase were produced at moderate temperatures, but the high temperature product was crystalline SiC.

Incorporation of organic linkers into the gels can be achieved by cross-linking dinuclear silicon reagents [239]: 


$$
n \mathrm{Cl}_{3} \mathrm{Si}\left(\mathrm{CH}_{2}\right)_{m} \mathrm{SiCl}_{3} \stackrel{\left(\mathrm{Me}_{3} \mathrm{Si}\right)_{2} \mathrm{NCN}}{\longrightarrow}\left[\mathrm{Si}\left(\mathrm{CH}_{2}\right)_{m} \mathrm{Si}(\mathrm{NCN})_{3}\right]_{n}(m=2,6 \text { or } 8)
$$

These formed gels, which could be freeze dried to produce hybrid alkyl silicon diimide materials, which were macroporous and had surface areas of $\sim 100 \mathrm{~m}^{2} \mathrm{~g}^{-1}$ [239]. Firing these potentially gives a route to increased carbon incorporation, e.g. for the battery applications described in section 3.3. There has been little work to utilise this carbodiimide-based sol-gel chemistry to process silicon carbonitrides. However the luminescence properties of materials based on $\left[\mathrm{Si}(\mathrm{NCN})_{2}\right]_{n}$ polymers have been examined - blue emission was observed in amorphous ceramics fired at low temperature such that they still contained NCN groups, and addition of $\mathrm{EuCl}_{3}$ to the monomer solution before gelation allowed the incorporation of $\mathrm{Eu}^{3+}$ ions with characteristic red emission [240].

In a number of cases silicon precursors can be subjected to hydroboration followed by reaction of the chloride groups with $\left(\mathrm{Me}_{3} \mathrm{Si}\right)_{2} \mathrm{NCN}$ to yield boron-silicon carbodiimide gels, these too have been then treated as powders [129].

\section{4. $\mathrm{Si}_{3} \mathrm{~B}_{3} \mathrm{~N}_{7}$ : a sol-gel derived preceramic polymer}

Ambient temperature ammonolysis of (trichlorosilyl)aminodichloroborane $\left(\mathrm{Cl}_{3} \mathrm{SiNHBCl}_{2}\right)$ followed by firing in ammonia results in $\mathrm{Si}_{3} \mathrm{~B}_{3} \mathrm{~N}_{7}$ [14]. Alternatively it can be produced from the co-ammonolysis of $\mathrm{Si}(\mathrm{NHMe})_{4}$ and $\mathrm{B}\left(\mathrm{NMe}_{2}\right)_{3}$ followed by firing in ammonia as described in section 4.1 [181]. Similarly to the heavily cross-linked gels produced with carbodiimide as described in section 4.3 , the polymers cannot be obtained as soluble species. Hence this material must be produced by this sol-gel type approach and then processed as a powder.

A number of crystalline phases of $\mathrm{Si}_{3} \mathrm{~B}_{3} \mathrm{~N}_{7}$ have been predicted [241], but it remains amorphous even when heated for extended periods at $1800^{\circ} \mathrm{C}$, with only $\mathrm{Si}_{3} \mathrm{~N}_{4}$ crystallising (at $\sim 1940{ }^{\circ} \mathrm{C}$ ) before decomposition with the loss of all nitrogen at $2000^{\circ} \mathrm{C}$ [14]. TEM shows no variations in elemental composition the amorphous phase, suggesting it to be homogeneous at the $\mathrm{nm}$ level, and PDF studies observe only Si-N, B-N and Si-Si distances [149]. Neutron PDF and MAS-NMR studies confirmed the structure to be random even at the shortest length scales [150,242-244], and this homogeneity even at the $\sim 1 \mathrm{~nm}$ length scale is likely responsible for the high temperature behaviour of the ceramic. The distribution has been explained in terms of the probability of the various reactions within the synthesis process [245]. Modelling has shown that ordered regions of $\sim 15 \mathrm{~nm}$ are necessary for the crystalline phases to become more stable than the amorphous [246]. Nonetheless some heterogeneity is suggested to occur at very short length scales $(<1 \mathrm{~nm})$ in the form of nanovoids and also of B-rich and Si-rich regions [244,247].

The use of a polymer-derived $\mathrm{Si}_{3} \mathrm{~B}_{3} \mathrm{~N}_{7}$ rather than a $\mathrm{Si}_{3} \mathrm{~N}_{4} / \mathrm{BN}$ mixture in production of nanocomposites allows better mechanical properties in the sintered pieces obtained by cold pressing (bending resistance $\sim 1000 \mathrm{MPa}$, Vickers' hardness $\sim 4 \mathrm{GPa}$ ) than those from the much more expensive hot pressing of the mixtures [14]. Calculations have suggested the bulk modulus of $\mathrm{Si}_{3} \mathrm{~B}_{3} \mathrm{~N}_{7}$ to be close to that of silicon nitride despite a density that is $\sim 8 \%$ lower [248]. Molecular dynamics simulations were then used to predict that less boron-rich phases generally had lower modulus values, and also to show that composites of $\mathrm{Si}_{3} \mathrm{~B}_{3} \mathrm{~N}_{7}$ with $\mathrm{BN}$ nanotubes would have an enhanced modulus $[249,250]$.

The photoluminescence spectrum of Si3B3N7 shows three distinct emissions corresponding to the nanoscale Si-rich, B-rich and intermediate domains [251]. Addition of the hexamethyldisilazides of $\mathrm{Eu}, \mathrm{Ce}$ or Tb resulted in bright phosphors in which the lanthanide ions were dispersed through an amorphous matrix [252]. Interestingly some of these phosphors showed different emission colours 
at different excitation wavelengths (Fig. 21). These were suggested to be strong options for phosphors in GaN-based LED light sources.

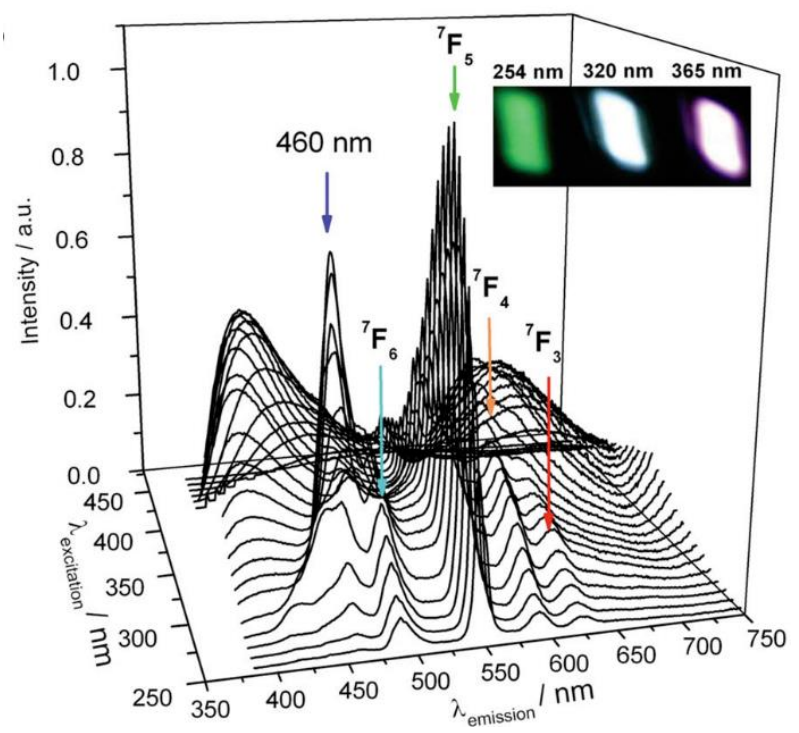

Figure 21: Photoluminescence spectra of $\mathrm{Tb}^{3+}$-doped amorphous $\mathrm{Si}_{3} \mathrm{~B}_{3} \mathrm{~N}_{7}$ ceramic showing the change in the spectrum with excitation wavelength and (inset) photographs showing the emission colour at various excitation wavelengths. Reproduced with kind permission from [252].

\section{Summary}

Silicon nitride and ternary and higher materials based on silicon nitride can be produced by an extensive range of reactions based on polymerisation processes. Typically these are referred to as preceramic processes where a polymer is produced in soluble or meltable form and then crosslinked during the formation of the desired structure, or as sol-gel when polymerisation occurs directly in solution to form a gel phase in which the network of bonds that define the shape of the final material is already defined. There are significant overlaps between these definitions. The preceramic polymer or dried gel is also sometimes then subjected to ceramic powder processing methods, in which case the distinction is somewhat academic.

Preceramic routes provide access to amorphous silicon nitride, carbonitride and borocarbonitride materials which can have high density or can be processed with a pore-forming component like a template or a filler to introduce porosity. These materials have many superior properties to the binary ceramics, including high temperature stability and mechanical properties. Significant effort has gone into production of these materials for the fibre or matrix components of composite materials. At high temperature crystallisation can provide access to composites and often ceramic yields are high, although loss of carbon or nitrogen under various regimes is common.

In some materials sol-gel methods are the only route to powdered materials that are then subjected to powder processing. Ammonolytic sol-gel processing from silicon amides has been shown to be capable of producing a range of useful morphologies including porous materials. The latter have been shown to have useful catalytic activities. Similarly using carbodiimide linkers has the capability to provide well controlled sol-gel processing. These methods have great scope for further development.

\section{Acknowledgements}


The author thanks EPSRC for supporting recent work on sol-gel silicon nitride based materials for catalysis applications under EP/J019208/1.

\section{References}

[1] D. Hardie, K.H. Jack, Nature 180 (1957) 332-333.

[2] A. Zerr, M. Kempf, M. Schwarz, E. Kroke, M. Göken, R. Riedel, J. Am. Ceram. Soc. 85 (2002) 86-90.

[3] A. Salamat, A.L. Hector, P. Kroll, P.F. McMillan, Coord. Chem. Rev. 257 (2013) 2063-2072.

[4] T. Nishimura, X. Xu, K. Kimoto, N. Hirosaki, H. Tanaka, Sci. Technol. Adv. Mater. 8 (2007) 635643.

[5] F.L. Riley, J. Am. Ceram. Soc. 83 (2004) 245-265.

[6] E.F. Krimmel, R. Hezel, Silicon: Silicon Nitride in Microelectronics and Solar Cells, Springer Science and Business Media, 2013.

[7] D. Probst, H. Hoche, Y. Zhou, R. Hauser, T. Stelzner, H. Scheerer, E. Broszeit, C. Berger, R. Riedel, H. Stafast, E. Koke, Surf. Coatings Technol. 200 (2005) 355-359.

[8] Y. Zhou, D. Probst, A. Thissen, E. Kroke, R. Riedel, R. Hauser, H. Hoche, E. Broszeit, P. Kroll, H. Stafast, J. Eur. Ceram. Soc. 26 (2006) 1325-1335.

[9] Y. Zhou, X. Yan, E. Kroke, R. Riedel, D. Probst, A. Thissen, R. Hauser, M. Ahles, H. von Seggern, Materwiss. Werksttech. 37 (2006) 173-177.

[10] X. Sun, H. Liu, J. Li, H. Cheng, Ceram. Int. 42 (2016) 82-89.

[11] G.-F. Lu, S.-R. Qiao, C.-Y. Zhang, G.-S. Jiao, J. Inorg. Mater. 26 (2011) 779-784.

[12] R. Riedel, G. Mera, R. Hauser, A. Klonczynski, J. Ceram. Soc. Japan 114 (2006) 425-444.

[13] J. Bill, T.W. Kamphowe, A. Müller, T. Wichmann, A. Zern, A. Jalowieki, J. Mayer, M. Weinmann, J. Schuhmacher, K. Müller, J. Peng, H.J. Seifert, F. Aldinger, Appl. Organomet. Chem. 15 (2001) 777-793.

[14] H.-P. Baldus, M. Jansen, Angewante Chemie Int. Ed. English 36 (1997) 328-343.

[15] P. Miele, S. Bernard, D. Cornu, B. Toury, Soft Mater. 4 (2007) 249-286.

[16] C. Vakifahmetoglu, Adv. Appl. Ceram. Struct. Funct. Bioceram. 110 (2011) 188-204.

[17] S. Bernard, P. Miele, New J. Chem. 38 (2014) 1923.

[18] C.J. Brinker, G.W. Scherer, Sol-Gel Science: The Physics and Chemistry of Sol-Gel Processing, Academic Press Inc, San Diego, 1990.

[19] A.E. Danks, S.R. Hall, Z. Schnepp, Mater. Horizons 3 (2016) 91-112.

[20] F. Schüth, Angew. Chemie - Int. Ed. 42 (2003) 3604-3622.

[21] R. Riedel, Naturwissenschaften 82 (1995) 12-20.

[22] U. Schubert, N. Husing, Synthesis of Inorganic Materials, 3rd ed., Wiley-VCH, Weinheim, 2012.

[23] A.L. Hector, Chem. Soc. Rev. 36 (2007) 1745-1753. 
[24] S. Schaible, R. Riedel, E. Werner, U. Klingebiel, Appl. Organomet. Chem. 7 (1993) 53-56.

[25] S. Kaskel, D. Farrusseng, K. Schlichte, Chem. Commun. (2000) 2481-2482.

[26] S. Kaskel, K. Schlichte, J. Catal. 201 (2001) 270-274.

[27] S. Kaskel, K. Schlichte, B. Zibrowius, Phys. Chem. Chem. Phys. 4 (2002) 1675-1681.

[28] B.M. Gray, S. Hassan, A.L. Hector, A. Kalaji, B. Mazumder, Chem. Mater. 21 (2009) 42104215.

[29] D. Peters, H. Jacobs, J. Less Common Met. 146 (1989) 241-249.

[30] S. Schaible, R. Riedel, R. Boese, E. Werner, U. Klingebiel, M. Nieger, Appl. Organomet. Chem. 8 (1994) 491-498.

[31] S. Kaskel, G. Chaplais, K. Schlichte, Chem. Mater. 17 (2005) 181-185.

[32] F. Cheng, S.M. Kelly, S. Clark, N.A. Young, S.J. Archibald, J.S. Bradley, F. Lefebvre, Chem. Mater. 17 (2005) 5594-5602.

[33] F. Cheng, C.N. Hope, S.J. Archibald, J.S. Bradley, S. Clark, M.G. Francesconi, S.M. Kelly, N.A. Young, F. Lefebvre, Int. J. Appl. Ceram. Technol. 8 (2011) 467-481.

[34] D. Seyferth, ACS Adv. Chem. 245 (1995) 131-160.

[35] W. Verbeek, Production of Shaped Articles of Homogeneous Mixtures of Silicon Carbide and Nitride, U.S. Patent 3,853,567, 1974.

[36] G. Winter, W. Werbeek, M. Mansmann, Production of Shaped Articles of Silicon Carbide and Silicon Nitride, U.S. Patent 3,892,583, 1976.

[37] T. Isoda, H. Kaya, H. Nishii, O. Funayama, T. Suzuki, Y. Tashiro, J. Inorg. Organomet. Polym. 2 (1992) 151-160.

[38] O. Funayama, Y. Tashiro, A. Kamo, M. Okumura, T. Isoda, J. Mater. Sci. 29 (1994) 4883-4888.

[39] Y. Yokoyama, T. Nanba, I. Yasui, H. Kaya, T. Maeshima, T. Isoda, J. Am. Ceram. Soc. 74 (1991) 654-657.

[40] C.R. Blanchard, S.T. Schwab, J. Am. Ceram. Soc. 77 (1994) 1729-1739.

[41] K. Sato, H. Kakisawa, Y. Kagawa, H. Kaya, O. Funayama, T. Isoda, J. Mater. Sci. Lett. 19 (2000) 1179-1183.

[42] S.T. Schwab, R.A. Page, Mater. Sci. Eng. A 204 (1995) 201-204.

[43] Z. Peng, N. Zhu, X. Fu, C. Wang, Z. Fu, L. Qi, H. Miao, J. Am. Ceram. Soc. 93 (2010) 2264-2267.

[44] N. Zhu, Z. Peng, C. Wang, Z. Fu, H. Miao, Solid State Sci. 11 (2009) 1094-1097.

[45] S.T. Schwab, C.R. Blanchard-Ardid, MRS Proc. 121 (1988) 581 (7 pages).

[46] S.T. Schwab, C.R. Blanchard, R.C. Graef, J. Mater. Sci. 29 (1994) 6320-6328.

[47] K. Sato, T. Suzuki, O. Funayama, T. Isoda, J. Ceram. Soc. Japan 100 (1992) 444-447.

[48] K. Sato, H. Morozumi, O. Funayama, T. Isoda, J. Ceram. Soc. Japan 110 (2002) 775-779.

[49] G.-J. Qi, C.R. Zhang, H.F. Hu, F. Coo, S.Q. Wang, Y.G. Jiang, Adv. Eng. Mater. 7 (2005) 10431046. 
[50] C. Salameh, A. Bruma, S. Malo, U.B. Demirci, P. Miele, S. Bernard, RSC Adv. 5 (2015) 5894358951.

[51] M. Günthner, K. Wang, R.K. Bordia, G. Motz, J. Eur. Ceram. Soc. 32 (2012) 1883-1892.

[52] K. Wang, X. Zheng, F.S. Ohuchi, R.K. Bordia, J. Am. Ceram. Soc. 95 (2012) 3722-3725.

[53] N. Shinde, Y. Takano, J. Sagan, V. Monreal, T. Nagahara, J. Photopolym. Sci. Technol. 23 (2010) 225-230.

[54] Z. Zhang, Z. Shao, Y. Luo, P. An, M. Zhang, C. Xu, Polym. Int. 64 (2015) 971-978.

[55] R. Riedel, G. Passing, H. Schönfelder, R.J. Brook, Nature 355 (1992) 714-717.

[56] M. Hörz, A. Zern, F. Berger, J. Haug, K. Müller, F. Aldinger, M. Weinmann, J. Eur. Ceram. Soc. 25 (2005) 99-110.

[57] G. Boden, G. Michael, T. Breuning, Ceram. Forum Int. 75 (1998) 24-29.

[58] N. Brodie, J.-P. Majoral, J.-P. Disson, Inorg. Chem. 32 (1993) 4646-4649.

[59] J. He, M. Scarlette, J.F. Harrod, J. Am. Ceram. Soc. 78 (1995) 3009-3017.

[60] Y. Li, E. Kroke, R. Riedel, C. Fasel, C. Gervais, F. Babonneau, Appl. Organomet. Chem. 15 (2001) 820-832.

[61] X. Fu, N. Zhu, Z. Peng, Solid State Sci. 14 (2012) 1267-1272.

[62] G.-J. Qi, C.R. Zhang, H.F. Hu, J. Non. Cryst. Solids 352 (2006) 3794-3798.

[63] R. Riedel, M. Seher, J. Mayer, D.V. Szabo, J. Eur. Ceram. Soc. 15 (1995) 703-715.

[64] H. Schonfelder, F. Aldinger, R. Riedel, J. Phys. IV Colloq. 3 (1993) 1293-1297.

[65] R. Riedel, H.J. Kleebe, H. Schonfelder, F. Aldinger, Nature 374 (1995) 526-528.

[66] J.P. Dismukes, J.W. Johnson, J.S. Bradley, J.M. Millar, Chem. Mater. 9 (1997) 699-706.

[67] J. Tsubaki, H. Mori, K. Ayama, T. Hotta, M. Naito, J. Memb. Sci. 129 (1997) 1-8.

[68] J.S. Bradley, O. Vollmer, R. Rovai, U. Specht, F. Lefebvre, Adv. Mater. 10 (1998) 938-942.

[69] D. Galusek, S. Reschke, R. Riedel, W. Dreßler, P. Šajgalík, Z. Lenčéš, J. Majling, J. Eur. Ceram. Soc. 19 (1999) 1911-1921.

[70] C. Konetschny, D. Galusek, S. Reschke, C. Fasel, R. Riedel, J. Eur. Ceram. Soc. 19 (1999) 27892796.

[71] C. Haluschka, H. Kleebe, R. Franke, R. Riedel, J. Eur. Ceram. Soc. 20 (2000) 1355-1364.

[72] K. Sato, H. Kaya, O. Funayama, T. Isoda, J. Ceram. Soc. Japan 109 (2001) 440-446.

[73] D. Galusek, F.L. Riley, R. Riedel, J. Am. Ceram. Soc. 84 (2001) 1164-1166.

[74] R. Raj, L. An, S. Shah, R. Riedel, C. Fasel, H.-J. Kleebe, J. Am. Ceram. Soc. 84 (2001) 1803-1810.

[75] M. Weinmann, A. Zern, F. Aldinger, Adv. Mater. 13 (2001) 1704-1708.

[76] M. Friess, J. Bill, J. Golczewski, A. Zimmermann, F. Aldinger, R. Riedel, R. Raj, J. Am. Ceram. Soc. 85 (2002) 2587-2589.

[77] S. Reschke, C. Haluschka, R. Riedel, Z. Lenčéš, D. Galusek, J. Eur. Ceram. Soc. 23 (2003) 1963- 
1970.

[78] G. Boden, A. Neumann, T. Breuning, E. Tschernikova, W. Hermel, J. Eur. Ceram. Soc. 18 (1998) 1461-1469.

[79] J. Haug, P. Lamparter, M. Weinmann, F. Aldinger, Chem. Mater. 16 (2004) 72-82.

[80] D.-L. Yang, D.-S. Tsai, H. Liu, J. Mater. Sci. 30 (1995) 4463-4468.

[81] J. Seitz, J. Bill, J. Mater. Sci. Lett. 15 (1996) 391-393.

[82] C. Gérardin, F. Taulelle, D. Bahloul, J. Mater. Chem. 7 (1997) 117-126.

[83] M.F. Gonon, S. Hampshire, J.P. Disson, G. Fantozzi, J. Eur. Ceram. Soc. 15 (1995) 683-688.

[84] G. Ziegler, H.-J. Kleebe, G. Motz, H. Müller, S. TraßI, W. Weibelzahl, Mater. Chem. Phys. 61 (1999) 55-63.

[85] H.J. Kleebe, H. Störmer, S. Trassl, G. Ziegler, Appl. Organomet. Chem. 15 (2001) 858-866.

[86] J. Wan, M.J. Gasch, A.K. Mukherjee, J. Am. Ceram. Soc. 85 (2002) 554-564.

[87] J. Wan, M.J. Gasch, C.E. Lesher, A.K. Mukherjee, J. Am. Ceram. Soc. 86 (2003) 857-863.

[88] W. Yang, Z. Xie, H. Miao, L. Zhang, H. Ji, L. An, J. Am. Ceram. Soc. 88 (2005) 466-469.

[89] W. Yang, Z. Xie, J. Li, H. Miao, L. Zhang, L. An, J. Am. Ceram. Soc. 88 (2005) 1647-1650.

[90] I.K. Sung, Christian, M. Mitchell, D.P. Kim, P.J.A. Kenis, Adv. Funct. Mater. 15 (2005) 13361342.

[91] D. Klaffke, W. Rolf, N. Janakiraman, F. Aldinger, Wear 260 (2006) 711-719.

[92] V. Bakumov, K. Gueinzius, C. Hermann, M. Schwarz, E. Kroke, J. Eur. Ceram. Soc. 27 (2007) 3287-3292.

[93] J. Yan, A. Wang, D. Kim, Microporous Mesoporous Mater. 100 (2007) 128-133.

[94] G.-S. Chung, Microelectronics J. 38 (2007) 888-893.

[95] J. Wan, P.R.L. Malenfant, S.T. Taylor, S.M. Loureiro, M. Manoharan, Mater. Sci. Eng. A 463 (2007) 78-88.

[96] Y. Wang, L. Zhang, W. Xu, T. Jiang, Y. Fan, D. Jiang, L. An, J. Am. Ceram. Soc. 91 (2008) 39713975.

[97] N. Janakiraman, F. Aldinger, J. Eur. Ceram. Soc. 29 (2009) 163-173.

[98] A. Francis, R. Riedel, J. Appl. Phys. 105 (2009) 1-4.

[99] C. Vakifahmetoglu, I. Menapace, A. Hirsch, L. Biasetto, R. Hauser, R. Riedel, P. Colombo, Ceram. Int. 35 (2009) 3281-3290.

[100] P.E. Sánchez-Jiménez, J.A. Downs, R. Raj, J. Am. Ceram. Soc. 93 (2010) 2567-2570.

[101] Y. Yu, Y. Chen, C. Xu, J. Fang, L. An, J. Am. Ceram. Soc. 94 (2011) 2779-2782.

[102] S. Jung, D. Seo, S.J. Lombardo, Z.C. Feng, J.K. Chen, Y. Zhang, Sensors Actuators, A Phys. 175 (2012) 53-59.

[103] Q. Li, X. Yin, W. Duan, B. Hao, L. Kong, X. Liu, J. Eur. Ceram. Soc. 34 (2014) 589-598. 
[104] L.H. Hu, R. Raj, J. Am. Ceram. Soc. 98 (2015) 1052-1055.

[105] T. Konegger, L.F. Williams, R.K. Bordia, J. Am. Ceram. Soc. 98 (2015) 3047-3053.

[106] D. Bahloul, M. Pereira, C. Gérardin, J. Mater. Chem. 7 (1997) 109-116.

[107] S.H. Baek, L.M. Reinold, M. Graczyk-Zajac, R. Riedel, F. Hammerath, B. Büchner, H.J. Grafe, J. Power Sources 253 (2014) 342-348.

[108] R.M. Laine, F. Babonneau, K.Y. Blowhowiak, R.A. Kennish, J.A. Rahn, G.J. Exarhos, K. Waldner, J. Am. Ceram. Soc. 78 (1995) 137-145.

[109] C. Xu, C. Liu, Z. Zheng, Y. Li, Z. Zhang, S. Yang, Z. Xie, J. Appl. Polym. Sci. 82 (2001) 2827-2831.

[110] H.-J. Kleebe, Phys. Status Solidi 166 (1998) 297-313.

[111] H. Kleebe, D. Suttor, H. Muller, G. Ziegler, J. Am. Ceram. Soc. 81 (1998) 2971-2977.

[112] T.P. Coons, J.W. Reutenauer, G. Richards, S. Frueh, S.L. Suib, J. Am. Ceram. Soc. 95 (2012) 3339-3345.

[113] J.E. Bender, W. Chin, M.M. Banaszak Holl, Chem. Mater. 11 (1999) 154-157.

[114] X. Bao, M.J. Edirisinghe, Compos. Part A 30 (1999) 601-610.

[115] X. Bao, M.J. Edirisinghe, Q. Mary, M. End, J. Mater. Chem. 10 (2000) 395-401.

[116] Y. Chen, X. Yang, Y. Cao, Z. Gan, L. An, Acta Mater. 72 (2014) 22-31.

[117] A. Lukacs III, Am. Ceram. Soc. Bull. 86 (2006) 9301-9306.

[118] L. An, R. Riedel, C. Konetschny, H.-J. Kleebe, R. Raj, J. Am. Ceram. Soc. 81 (2005) 1349-1352.

[119] C. Haluschka, C. Engel, R. Riedel, J. Eur. Ceram. Soc. 20 (2000) 1355-1374.

[120] R. Kolb, C. Fasel, V. Liebau-Kunzmann, R. Riedel, J. Eur. Ceram. Soc. 26 (2006) 3903-3908.

[121] G. Liu, J. Kaspar, L.M. Reinold, M. Graczyk-Zajac, R. Riedel, Electrochim. Acta 106 (2013) 101108.

[122] L.M. Reinold, M. Graczyk-zajac, Y. Gao, G. Mera, R. Riedel, J. Power Sources 236 (2013) 224229.

[123] M. Graczyk-Zajac, L.M. Reinold, J. Kaspar, P.V.W. Sasikumar, G. Soraru, R. Riedel, Nanomaterials 5 (2015) 233-245.

[124] M. Graczyk-Zajac, M. Wimmer, C. Neumann, R. Riedel, J. Solid State Electrochem. 19 (2015) 2763-2769.

[125] V. Liebau-Kunzmann, C. Fasel, R. Kolb, R. Riedel, J. Eur. Ceram. Soc. 26 (2006) 3897-3901.

[126] U. Degenhardt, F. Stegner, C. Liebscher, U. Glatzel, K. Berroth, W. Krenkel, G. Motz, J. Eur. Ceram. Soc. 32 (2012) 1893-1899.

[127] D. Su, Y. Li, F. Hou, X. Yan, J. Am. Ceram. Soc. 97 (2014) 1311-1316.

[128] C. Wang, N. Song, L. Ni, C. Bao, High Perform. Polym. 28 (2016) 359-367.

[129] R. Riedel, E. Kroke, A. Greiner, A.O. Gabriel, L. Ruwisch, J. Nicolich, P. Kroll, Chem. Mater. 10 (1998) 2964-2979.

[130] A.O. Gabriel, R. Riedel, W. Dressler, S. Reichert, C. Gervais, J. Maquet, F. Babonneau, Chem. 
Mater. 11 (1999) 412-420.

[131] R.M. Morcos, G. Mera, A. Navrotsky, T. Varga, R. Riedel, F. Poli, K. Müller, J. Am. Ceram. Soc. 91 (2008) 3349-3354.

[132] S. Sen, S. Widgeon, Nanomaterials 5 (2015) 366-375.

[133] Y. Iwamoto, W. Vo, E. Kroke, R. Riedel, T. Saitou, K. Matsunaga, J. Am. Ceram. Soc. 84 (2001) 2170-2178.

[134] G. Mera, R. Ishikawa, E. Ionescu, Y. Ikuhara, R. Riedel, J. Eur. Ceram. Soc. 35 (2015) 33553362.

[135] G. Mera, R. Riedel, F. Poli, K. Müller, J. Eur. Ceram. Soc. 29 (2009) 2873-2883.

[136] S. Widgeon, G. Mera, Y. Gao, E. Stoyanov, S. Sen, A. Navrotsky, R. Riedel, Chem. Mater. 24 (2012) 1181-1191.

[137] R.M. Prasad, G. Mera, K. Morita, M. Müller, H.-J. Kleebe, A. Gurlo, C. Fasel, R. Riedel, J. Eur. Ceram. Soc. 32 (2012) 477-484.

[138] A. Klausmann, K. Morita, K.E. Johanns, C. Fasel, K. Durst, G. Mera, R. Riedel, E. lonescu, J. Eur. Ceram. Soc. 35 (2015) 3771-3780.

[139] M. Graczyk-Zajac, G. Mera, J. Kaspar, R. Riedel, J. Eur. Ceram. Soc. 30 (2010) 3235-3243.

[140] J. Kaspar, G. Mera, A.P. Nowak, M. Graczyk-Zajac, R. Riedel, Electrochim. Acta 56 (2010) 174182.

[141] M. Jansen, H. Juengermann, Curr. Opin. Solid State Mater. Sci. 2 (1997) 150-157.

[142] M. Weinmann, M. Kroschel, T. Jäschke, J. Nuss, M. Jansen, G. Kolios, A. Morillo, C. Tellaeche, U. Nieken, J. Mater. Chem. 18 (2008) 1810-1818.

[143] Y. Hasegawa, J. Ceram. Soc. Japan 114 (2006) 480-486.

[144] M. Weinmann, R. Haug, J. Bill, F. Aldinger, J. Schuhmacher, K. Muller, J. Organomet. Chem. 541 (1997) 345-353.

[145] O. Funayama, H. Nakahara, M. Okoda, M. Okumura, T. Isoda, J. Mater. Sci. 30 (1995) 410416.

[146] R. Jansen, M. Kroschel, Zeitschrift Fur Anorg. Und Allg. Chemie 626 (2000) 1634-1638.

[147] L. Gottardo, S. Bernard, C. Gervais, M. Weinmann, P. Miele, J. Mater. Chem. 22 (2012) 17923.

[148] Y.H. Sehlleier, A. Verhoeven, M. Jansen, J. Mater. Chem. 17 (2007) 4316-4319.

[149] D. Heinemann, W. Assenmacher, W. Mader, M. Kroschel, M. Jansen, J. Mater. Res. 14 (1999) 3746-3753.

[150] R.M. Hagenmayer, U. Müller, C.J. Benmore, J. Neuefeind, M. Jansen, J. Mater. Chem. 9 (1999) 2865-2869.

[151] G. Jeschke, M. Kroschel, M. Jansen, J. Non-Cryst. Solids 260 (1999) 216-227.

[152] J. Schuhmacher, F. Berger, M. Weinmann, J. Bill, F. Aldinger, K. Müller, Appl. Organomet. Chem. 15 (2001) 809-819.

[153] F. Berger, A. Müller, F. Aldinger, K. Müller, Zeitschrift Fur Anorg. Und Allg. Chemie 631 (2005) 355-363. 
[154] A. Hannemann, J.C. Schon, M. Jansen, H. Putz, T. Lengauer, Phys. Rev. B - Condens. Matter Mater. Phys. 70 (2004) 144201 (13 pages).

[155] A. Zern, J. Mayer, N. Janakiraman, M. Weinmann, J. Bill, M. Rühle, J. Eur. Ceram. Soc. 22 (2002) 1621-1629.

[156] S. Widgeon, G. Mera, Y. Gao, S. Sen, A. Navrotsky, R. Riedel, J. Am. Ceram. Soc. 96 (2013) 1651-1659.

[157] H. Schmidt, Soft Mater. 4 (2007) 143-164.

[158] N. Janakiraman, M. Weinmann, J. Schuhmacher, K. Muller, J. Bill, F. Aldinger, J. Am. Ceram. Soc. 85 (2002) 1807-1814.

[159] A. Jalowiecki, J. Bill, M. Friess, J. Mayer, F. Aldinger, R. Riedel, Nanostructured Mater. 6 (1995) 279-282.

[160] T. Wideman, P.J. Fazen, K. Su, E.E. Remsen, G.A. Zank, L.G. Sneddon, Appl. Organomet. Chem. 12 (1998) 681-693.

[161] Z.C. Wang, F. Aldinger, R. Riedel, J. Am. Ceram. Soc. 84 (2001) 2179-2183.

[162] M. Weinmann, J. Schuhmacher, H. Kummer, S. Prinz, J. Peng, H. Jurgen Seifert, M. Christ, K. Muller, J. Bill, F. Aldinger, Chem. Mater. 12 (2000) 623-632.

[163] A. Muller, P. Gerstel, M. Weinmann, J. Bill, F. Aldinger, J. Eur. Ceram. Soc. 21 (2001) 21712177.

[164] T. Jäschke, M. Jansen, Comptes Rendus Chim. 7 (2004) 471-482.

[165] S. Mann, D. Geilenber, J.A.C. Broekart, M. Jansen, J. Anal. At. Spectrosc. 12 (1997) 975-979.

[166] R. Riedel, L.M. Ruswisch, L.N. An, R. Raj, J. Am. Ceram. Soc. 81 (1998) 3341-3344.

[167] R. Weisbarth, M. Jansen, J. Mater. Chem. 13 (2003) 2975.

[168] T. Jaschke, M. Jansen, J. Eur. Ceram. Soc. 25 (2005) 211-220.

[169] T. Jaschke, M. Jansen, J. Mater. Chem. 16 (2006) 2792-2799.

[170] A. Roth, M. Jansen, A. Apple, Molecular Borosilacarbazane Compounds with a Fused Tricyclic Structure, Used as Precursors for Heat-Resistant Ceramic Products such as Fibres, Coatings, Mouldings and Sheet Materials, DE102006013469-A1; WO2007110183-A1, 2007.

[171] Q.D. Nghiem, J.K. Jeon, L.Y. Hong, D.P. Kim, J. Organomet. Chem. 688 (2003) 27-35.

[172] J. Kong, M. Wang, J. Zou, L. An, ACS Appl. Mater. Interfaces 7 (2015) 6733-6744.

[173] S. Bernard, M. Weinmann, D. Cornu, P. Miele, Adv. Sci. Technol. 50 (2006) 9-16.

[174] M. Weinmann, T.W. Kamphowe, J. Schuhmacher, K. Muller, F. Aldinger, Chem. Mater. 12 (2000) 2112-2122.

[175] Y.G. Jiang, C.R. Zhang, F. Cao, S.Q. Wang, G.-J. Qi, Y.B. Cao, Mater. Sci. Technol. 23 (2007) 880-882.

[176] Y. Jiang, C. Zhang, F. Cao, S. Wang, H. Hu, G.-J. Qi, Sci. China, Ser. E Technol. Sci. 51 (2008) 4045.

[177] X. Bin Yan, L. Gottardo, S. Bernard, P. Dibandjo, A. Brioude, H. Moutaabbid, P. Miele, Chem. Mater. 20 (2008) 6325-6334. 
[178] P.A. Ramakrishnan, Y.T. Wang, D. Balzar, L. An, C. Haluschka, R. Riedel, A.M. Hermann, Appl. Phys. Lett. 78 (2001) 3076-3078.

[179] R. Bhandavat, G. Singh, ACS Appl. Mater. Interfaces 4 (2012) 5092-5097.

[180] L. David, S. Bernard, C. Gervais, P. Miele, G. Singh, J. Phys. Chem. C 119 (2015) 2783-2791.

[181] J. Loeffelholz, M. Jansen, Adv. Mater. 7 (1995) 289-292.

[182] C.L. Czekaj, M.L.J. Hackney, W.J. Hurley Jr, L. V Interrante, G.A. Sigel, P.J. Schields, G.A. Slack, J. Am. Ceram. Soc. 73 (1990) 352-357.

[183] Y. Mori, T. Ueda, S. Kitaoka, Y. Sugahara, J. Ceram. Soc. Japan 114 (2006) 497-501.

[184] O. Majoulet, C. Salameh, M.E. Schuster, U.B. Demirci, Y. Sugahara, S. Bernard, P. Miele, Chem. Mater. 25 (2013) 3957-3970.

[185] F. Berger, M. Weinmann, F. Aldinger, K. Müller, Chem. Mater. 16 (2004) 919-929.

[186] Y. Tian, G. Shao, X. Wang, L. An, J. Micromechanics Microengineering 23 (2013) 095035 (6 pages).

[187] Y. Iwamoto, K.-I. Kikuta, S.-I. Hirano, J. Ceram. Soc. Japan 108 (2000) 350-356.

[188] K. Sato, T. Saitoh, T. Nagano, Y. Iwamoto, J. Ceram. Soc. Japan 114 (2006) 502-506.

[189] N. Hering, K. Schreiber, R. Riedel, O. Lichtenberger, J. Woltersdorf, Appl. Organomet. Chem. 15 (2001) 879-886.

[190] C. Zhou, X. Gao, Y. Xu, G. Buntkowsky, Y. Ikuhara, R. Riedel, E. Ionescu, J. Eur. Ceram. Soc. 35 (2015) 2007-2015.

[191] J. Yuan, S. Hapis, H. Breitzke, Y. Xu, C. Fasel, H. Kleebe, G. Buntkowsky, R. Riedel, E. lonescu, Inorg. Chem. 53 (2014) 10443-10455.

[192] J. Yuan, X. Luan, R. Riedel, E. Ionescu, J. Eur. Ceram. Soc. 35 (2015) 3329-3337.

[193] X. Long, C. Shao, H. Wang, J. Wang, Dalt. Trans. 44 (2015) 15463-15469.

[194] R. Hauser, A. Francis, R. Theismann, R. Riedel, J. Mater. Sci. 43 (2008) 4042-4049.

[195] A. Francis, E. Lonescu, C. Fasel, R. Riedel, Inorg. Chem. 48 (2009) 10078-10083.

[196] C. Zhou, L. Yang, H. Geng, Q. Zheng, H. Min, Z. Yu, H. Xia, Ceram. Int. 38 (2012) 6815-6822.

[197] Y. Li, Z. Zhen, C. Reng, Z. Zhang, W. Gao, S. Yang, Z. Xie, Appl. Organomet. Chem. 17 (2003) 120-126.

[198] M.S. Bazarjani, H. Kleebe, M.M. Mathis, C. Fasel, M.B. Yazdi, A. Gurlo, R. Riedel, Chem. Mater. 23 (2011) 4112-4123.

[199] M. Seifollahi Bazarjani, M.M. Müller, H.J. Kleebe, Y. Jüttke, I. Voigt, M. Baghaie Yazdi, L. Alff, R. Riedel, A. Gurlo, ACS Appl. Mater. Interfaces 6 (2014) 12270-12278.

[200] J.M. Gao, H.N. Xiao, I. Zhang, H.Q. Du, Trans. Nonferrous Met. Soc. China 7 (1997) 21-24.

[201] J. Gao, H. Xiao, H. Du, Ceram. Int. 29 (2003) 655-661.

[202] J. Li, R. Riedel, J. Am. Ceram. Soc. 90 (2007) 3786-3792.

[203] F. Wang, G.Q. Jin, X.Y. Guo, Mater. Lett. 60 (2006) 330-333. 
[204] M.G. Chaudhuri, R. Dey, M.K. Mitra, G.C. Das, S. Mukherjee, Sci. Technol. Adv. Mater. 9 (2008) 015002.

[205] Z. Omidi, A. Ghasemi, S. Reza Bakhshi, J. Sol-Gel Sci. Technol. 64 (2012) 245-250.

[206] M. Fukushima, Y.I. Yoshizawa, P. Colombo, J. Am. Ceram. Soc. 95 (2012) 3071-3077.

[207] K. Sardar, R. Bounds, M. Carravetta, G. Cutts, J.S.J. Hargreaves, A.L. Hector, J.A. Hriljac, W. Levason, F. Wilson, Dalt. Trans. 45 (2016) 5765-5774.

[208] R. Rovai, C.W. Lehmann, J.S. Bradley, Angew. Chemie - Int. Ed. 38 (1999) 2036-2038.

[209] F. Cheng, S.M. Kelly, F. Lefebvre, A.F. Lee, K. Wilson, S. Clark, J.S. Bradley, J. Mater. Chem. 15 (2005) 3039-3044.

[210] S. Hassan, A.L. Hector, J.R. Hyde, A. Kalaji, D.C. Smith, Chem. Commun. (Camb). (2008) 53045306.

[211] S. Hassan, A.L. Hector, A. Kalaji, J. Mater. Chem. 21 (2011) 6370.

[212] F. Cheng, S.M. Kelly, S. Clark, J.S. Bradley, F. Lefebvre, J. Organomet. Chem. 692 (2007) 38163822.

[213] O. Vollmer, F. Lefebvre, J.S. Bradley, in:, J. Mol. Catal. A Chem., 1999, pp. 87-96.

[214] F. Cheng, S. Clark, S.M. Kelly, J.S. Bradley, J. Am. Ceram. Soc. 1417 (2004) 1413-1417.

[215] D. Farrusseng, K. Schlichte, B. Spliethoff, A. Wingen, S. Kaskel, J.S. Bradley, F. Schüth, Angew. Chemie - Int. Ed. 40 (2001) 4204-4207.

[216] F. Cheng, S.M. Kelly, S. Clark, J.S. Bradley, M. Baumbach, A. Schutze, J. Memb. Sci. 280 (2006) 530-535.

[217] S.M. Kelly, F. Cheng, S.P. Kitney, V. Rocher, Chromatographic Separation Used for Chemical Components, Involves Provision of Chromatograph with Stationary Phase Including Mesoporous Silicon Imido Nitride, Silicon Diimide Mesoporous Gel or Silicon Nitride Mesoporous Ceramic, WO2013054129-A1, 2013.

[218] V. Rocher, S.M. Kelly, A.L. Hector, Microporous Mesoporous Mater. 156 (2012) 196-201.

[219] V.L. Nguyen, E. Zera, A. Perolo, R. Campostrini, W. Li, G. Domenico Soraru, J. Eur. Ceram. Soc. 35 (2015) 3295-3302.

[220] F. Cheng, B. Toury, F. Lefebvre, J.S. Bradley, Chem. Commun. (2003) 242-243.

[221] F. Cheng, S.M. Kelly, F. Lefebvre, B. Toury, J.S. Bradley, J. Ceram. Soc. Japan 114 (2006) 545548.

[222] F. Cheng, S.J. Archibald, S. Clark, B. Toury, S.M. Kelly, J.S. Bradley, Chem. Mater. 15 (2003) 4651-4657.

[223] F. Cheng, S.M. Kelly, F. Lefebvre, S. Clark, R. Supplit, J.S. Bradley, J. Mater. Chem. 15 (2005) 772-777.

[224] A.W. Jackson, A.L. Hector, J. Mater. Chem. 17 (2007) 1016.

[225] C.F. Mallinson, B.M. Gray, A.L. Hector, M.A. Mclachlan, J.R. Owen, Inorg. Chem. (2013) 99949999.

[226] J. Löffelholz, J. Engering, M. Jansen, Zeitschrift Für Anorg. Und Allg. Chemie 626 (2000) 963- 
968.

[227] J. Engering, M. Jansen, Zeitschrift Fur Anorg. Und Allg. Chemie 629 (2003) 913-922.

[228] S. Hassan, M. Carravetta, A.L. Hector, L.A. Stebbings, J. Am. Ceram. Soc. 93 (2010) 1069-1073.

[229] A.W. Jackson, O. Shebanova, A.L. Hector, P.F. McMillan, J. Solid State Chem. 179 (2006) 1383-1393.

[230] D. V Baxter, M.H. Chisholm, G.J. Gama, V.F. Distasi, A.L. Hector, I.P. Parkin, Chem. Mater. 8 (1996) 1222-1228.

[231] J.S.J. Hargreaves, Coord. Chem. Rev. 257 (2013) 2015-2031.

[232] B. Mazumder, A.L. Hector, Top. Catal. 52 (2009) 1472-1481.

[233] S.I.U. Shah, A.L. Hector, Top. Catal. 55 (2012) 950-954.

[234] F. Cheng, S.M. Kelly, N.A. Young, S. Clark, M.G. Francesconi, F. Lefebvre, J.S. Bradley, Chem. Commun. (2005) 5662-5664.

[235] F. Cheng, S.M. Kelly, N.A. Young, C.N. Hope, K. Beverley, M.G. Francesconi, S. Clark, J.S. Bradley, F. Lefebvre, Chem. Mater. 18 (2006) 5996-6005.

[236] A.O. Gabriel, R. Riedel, Angewante Chemie Int. Ed. English 36 (1997) 384-386.

[237] A.O. Gabriel, R. Riedel, S. Storck, W.F. Maier, Appl. Organomet. Chem. 11 (1997) 833-841.

[238] C.L. Schmidt, M. Jansen, Appl. Organomet. Chem. 27 (2013) 141-147.

[239] S. Nahar-Borchert, E. Kroke, R. Riedel, B. Boury, R.J.P. Corriu, J. Organomet. Chem. 686 (2003) 127-133.

[240] Y. Shimokawa, A. Fujiwara, E. Ionescu, G. Mera, S. Honda, Y. Iwamoto, R. Riedel, J. Ceram. Soc. Japan 122 (2014) 895-901.

[241] P. Kroll, R. Hoffmann, Angew. Chemie - Int. Ed. 37 (1998) 2527-2530.

[242] R.M. Hagenmayer, U. Müller, M. Jansen, Phys. B Condens. Matter 276-278 (2000) 423-424.

[243] U. Müller, W. Hoffbauer, M. Jansen, Chem. Mater. 12 (2000) 2341-2346.

[244] M. Doerr, C.M. Marian, J. Phys. Condens. Matter 19 (2007) 056201 (22 pages).

[245] A. Hannemann, J.C. Schon, M. Jansen, J. Mater. Chem. 15 (2005) 1167-1178.

[246] A. Hannemann, J.C. Schon, M. Jansen, Philos. Mag. 88 (2008) 1037-1057.

[247] A. Hannemann, J.C. Schön, M. Jansen, Philos. Mag. 85 (2005) 2621-2639.

[248] P. Kroll, J. Eur. Ceram. Soc. 25 (2005) 163-174.

[249] M. Griebel, J. Hamaekers, Comput. Mater. Sci. 39 (2007) 502-517.

[250] N. Liao, W. Xue, M. Zhang, Model. Simul. Mater. Sci. Eng. 20 (2012) 035009 (7 pages).

[251] H. Cakmak, M. Jansen, J. Lumin. 130 (2010) 2322-2326.

[252] H. Cakmak, M. Jansen, Adv. Funct. Mater. 24 (2014) 460-464. 